\title{
Proyecto “Arqueometalurgia de la Península Ibérica” (1982-2017)
}

\author{
The Archaeometallurgical project of the Iberian Peninsula (1982-2017)
}

\author{
Salvador Rovira Llorens ${ }^{a}$ e Ignacio Montero Ruiz
}

\author{
A Manuel Fernández-Miranda, in memo- \\ riam.
}

\section{RESUMEN}

El proyecto "Arqueometalurgia de la Península Ibérica" empezó en 1982 con el propósito de estudiar la tecnología metalúrgica durante la Prehistoria y cubrir la limitación de datos existentes en comparación con otros países europeos cuya investigación se había iniciado en décadas anteriores. Inicialmente centrado en el Calcolítico y la Edad del Bronce y prestando atención a los restos metalúrgicos y no solo a los objetos de metal, también ha analizado materiales de periodos más recientes. Mediante el análisis elemental por fluorescencia de rayos-X (XRF por sus siglas en inglés), el uso de la metalografía óptica y posteriormente de la microscopía electrónica de barrido (SEM por sus siglas en inglés), los análisis de isótopos de plomo y los test de microdureza se ha recopilado un gran volumen de información durante estos 35 años de continuo funcionamiento: cerca de 24.000 XRF análisis y 900 metalografías. El proyecto ha contribuido de manera decisiva a la interpretación de la tecnología metalúrgica y ha aportado información básica en los debates sobre la intencionalidad o no de los cobres arsenicales, las estructuras de combustión utilizadas en la primera metalurgia o la escala de la producción metalúrgica y su influencia tanto en el medio ambiente como en los procesos sociales que se desarrollan en la Prehistoria peninsular.

\begin{abstract}
"The Archaeometallurgical project of the Iberian Peninsula" started in 1982. Its aim was to study the prehistoric metallurgical technology and to expand the that time limited number of analyses in comparison with other European countries with more developed research. Initially the focus
\end{abstract}

was Chalcolithic and Bronze Age metallurgy, analyzing metallurgical remains as well as the metal artifacts, but it has now expanded its scope to more recent periods. The maintechniques used over the 25 years of the project were XRF for elemental analysis (around 24,000 results), metallography (900) and scanning electron microscopy (SEM), lead isotopes analysis and micro-hardness test. The project has contributed in a decisive manner to the interpretation of the metallurgical technology. The information obtained supported the point of view that arsenic was a natural alloy, permitted the definition of the metallurgical structures during the early metallurgy, and established the scale of the production and the impact of metallurgy on the environment and social organization of later prehistoric Iberia.

Palabras clave: Análisis elemental; Metalografía; Isótopos de plomo; Cobres arsenicales; Vasijas de reducción; Tecnología metalúrgica; Bases de datos; Prehistoria.

Key words: Elemental analysis; Metallography; Lead isotopes; Arsenical copper; Smelting vessels; Metallurgical technology; Databases; Prehistory.

\section{LA GÉNESIS DEL PROYECTO}

En la década de 1970 la Arqueometría como ciencia auxiliar aplicada a la investigación arqueológica había tomado ya altos vuelos. Una de sus ramas, la Arqueometalurgia, seguía su progresión ascendente. La publicación del volumen de Otto y Witter (1952) dio el pistoletazo de salida hacia el creciente interés por el análisis de metales arqueológicos. Reunía una primera e importante colección de análisis de objetos prehistóricos de Europa Central y trataba de establecer, a partir de la composición del metal, su procedencia, relaciones culturales y otros aspectos (Pernicka 2014: 240).

a Investigador jubilado. Correo e.: s_rovirallorens@hotmail.com https://orcid.org/0000-0003-2463-0501

b CSIC, Instituto de Historia. C/ Albasanz 26-28. 28037 Madrid. Correo e.: ignacio.montero@cchs.csic.es https://orcid.org/ 0000-0003-0897-1031

Recibido 27-XI-2017; aceptado 18-I-2018. 
La década de 1950 y 1960 fue pródiga en avances en el equipamiento de los laboratorios. Los ya veteranos espectroscopios de emisión renovaron sus aplicaciones y se desarrollaron las técnicas de absorción. A mediados de la década de 1960 hizo su aparición la espectroscopía por fluorescencia de rayos-X (Montero Ruiz et al. 2007), una técnica que pronto captó el interés de arqueólogos y museos porque por primera vez se hacía fácilmente asequible un método no invasivo de análisis, liberando a las piezas metálicas de la servidumbre de ser sometidas a la extracción de muestras.

En aquellos años comenzaron a editarse revistas especializadas siendo quizás una de las más veteranas Archaeometry, aparecida en 1958 y publicada por el Research Laboratory for Archaeology and the History of Art de la Universidad de Oxford. Desde entonces hasta la actualidad el número de publicaciones periódicas, monografías especializadas y reuniones científicas ha crecido espectacularmente. En este giro metodológico de la investigación, orientado hacia la Arqueometría, tuvieron mucho que ver las influencias de teóricos como Clarke (1968) y las ideas de la New Archaeology que llegaban de Estados Unidos (p. ej. Chang 1967 y Watson et al. 1971, por mencionar un par de libros que poco después se tradujeron al castellano por Miguel Rivera Dorado).

En aquellos primeros años la Península Ibérica fue sujeto paciente. Se requeriría la minuciosa pesquisa de un doctorando especializado para rastrear los pocos estudios analíticos de materiales arqueológicos publicados en España, generalmente aparecidos en revistas ajenas al campo estrictamente arqueológico o como apéndices en alguna monografía. Decíamos lo de sujeto paciente porque, también desde la década de 1950, S. Junghans, E. Sangmeister y M. Schröder iniciaron un ambicioso proyecto para analizar metales prehistóricos de toda Europa, que culminó en una base de datos de más de 25.000 análisis. Sus resultados y su interpretación fueron publicados en sucesivos volúmenes de la serie Studien zu den Anfängen der Metallurgie (SAM) (para los objetos de base cobre Junghans et al. 1960, 1968, 1974; para los de oro Hartmann 1970, 1982) ${ }^{1}$. Todo lo que se sabía sobre los inicios de la metalurgia en la Península Ibérica, extraído de los resultados de dicho proyecto, fue sintetizado por Blance (1974), quien ya muchos años antes estaba persuadida de la importancia de los análisis de laboratorio de metales (Blance 1959).

En la década de 1970 Beno Rothenberg y Antonio Blanco Freijeiro dirigieron un proyecto orientado

\footnotetext{
${ }^{1}$ Los análisis efectuados por el proyecto $S A M$ fueron 516 objetos de base cobre y 550 de oro de España, y 843 objetos de base cobre y 325 de oro de Portugal. Algunos resultados fueron publicados en revistas antes de su recopilación en los libros de la serie SAM. Por ejemplo, Almagro Basch (1958) publicó los análisis de San Esteban de Río Sil y Hartmann y Kalb (1969) los de orfebrería peninsular en un trabajo pionero.
}

a la prospección y el estudio de materiales recopilados de una extensa área de la provincia de Huelva donde la minería y la metalurgia han tenido gran desarrollo desde la Prehistoria hasta tiempos modernos (Blanco Feijeiro y Rothenberg 1981). En aquel proyecto colaboraron numerosos técnicos españoles e ingleses y es de justicia mencionar que uno de ellos fue María Dolores Fernández-Posse, quien poco después sería miembro importante en la gestación y desarrollo del "Proyecto Arqueometalurgia de la Península Ibérica".

En ese caldo de cultivo, un grupo de investigadores integrado por Concepción Martín, María Dolores Fernández-Posse, María Luisa Ruiz-Gálvez, Germán Delibes de Castro y Salvador Rovira Llorens, liderado por Manuel Fernández-Miranda (a la sazón Subdirector General de Arqueología del Ministerio de Cultura) pensó que había llegado el momento de poner en pie un proyecto financiado desde dicha Subdirección para el análisis sistemático de los objetos de metal prehistóricos de las colecciones de los museos españoles. Se había dado la feliz circunstancia de que en 1981 se gestionó con éxito, desde la Subdirección General de Arqueología, la adquisición de un espectrómetro de fluorescencia de rayos- $\mathrm{X}$, aprovechando la entonces vigente Ayuda Americana como compensación por el arrendamiento de las bases militares que Estados Unidos tenía estratégicamente radicadas en España.

El equipo quedó instalado en el Instituto de Conservación y Restauración de Obras de Arte (ICROA, actual IPCE), que ocupaba parte del edificio del Museo de América de Madrid, y debemos a los buenos oficios de su director José María Cabrera y de María Sanz Nájera, jefa del Departamento de Arqueología, que el "Proyecto Arqueometalurgia de la Península Ibérica" (en adelante PA) echara a andar en febrero de 1982 con el compromiso de dar servicio también a dicho Instituto y aprovechar otros recursos en equipamiento de su laboratorio.

El PA nunca ha tenido una sede propia. Siempre se ha beneficiado de las instalaciones en las que han ido recalando sus miembros a lo largo de su andadura profesional, y debemos agradecer enormemente a los museos y centros de investigación en los que hemos trabajado (ICROA, Instituto del Patrimonio Histórico Español - IPHE-, Museo de América, Museo Arqueológico Nacional e Instituto de Historia del CSIC) no sólo su apoyo incondicional a la labor sino también las inversiones en equipamiento, siempre cuantiosas, para seguir progresando.

\section{OBJETIVOS DEL PROYECTO DE ARQUEOMETALURGIA}

Como hemos adelantado, en un principio los objetivos se cifraban en el análisis de las colecciones prehistóricas de los museos con la finalidad de crear una base 
de datos propia que incrementara el volumen de información ya publicado por los investigadores alemanes del $S A M$, atendiera a los intereses de los investigadores del propio grupo y a los de otros investigadores interesados en utilizar estas nuevas posibilidades. Así fue cómo entre las tareas iniciales acometimos el análisis de la parte del Depósito de la Ría de Huelva custodiada en el Museo Arqueológico Nacional (Rovira 1995) y los materiales recuperados en las últimas excavaciones de Almizaraque (Cuevas de Almanzora, Almería) (Delibes et al. 1986), así como los de excavaciones anteriores custodiados en museos (Delibes et al. 1989; Castaño et al. 1991). Pero pronto fuimos conscientes de que debíamos atender las necesidades analíticas de otros periodos culturales, abriendo el PA sin limitación temporal.

Poco a poco los objetivos fueron ampliándose conforme la propia evolución de la investigación arqueometalúrgica lo reclamaba. A diferencia de los grandes proyectos analíticos mencionados cuyo objetivo prioritario era estudiar la circulación y movimiento de los metales a partir de su composición, el PA tuvo desde su inicio un claro interés por la evolución de la tecnología. Primero fue incluir la metalografía microscópica, imprescindible para avanzar en el conocimiento de las técnicas de fabricación de los objetos. Luego, resultaba evidente que debíamos investigar los procedimientos usados por los metalurgos para transformar el mineral en metal, un tema en el que hasta hace bien poco había muchas y grandes lagunas y todavía las sigue habiendo, aunque menos. Pieza clave para esta línea de investigación son las escorias y otros residuos de la actividad metalúrgica, incluyéndolas desde mediados de la década de 1990 como objetivo importante, en particular las datadas en los periodos más antiguos de la producción de metal, bien sea cobre, estaño o hierro.

A lo largo de los años hemos ido sumando objetivos parciales, acercándonos cada vez más al concepto global y comprehensivo que define la Arqueometalurgia como el estudio de la historia y prehistoria del uso y producción de metales. Asumir la Arqueometalurgia como objetivo final de la investigación supone ser conscientes de que ello implica utilizar medios analíticos no disponibles en nuestro laboratorio y esto ha llevado a establecer vínculos y colaboraciones con otros laboratorios mejor equipados o más especializados para, entre todos, lograr los fines propuestos.

\section{EVOLUCIÓN DEL EQUIPAMIENTO, METODOLOGÍA Y SEDES}

\subsection{Análisis de la composición química}

En febrero de 1982 quedó instalado en el ICROA el espectrómetro multicanal Kevex 7000 de fluorescencia de rayos-X en energía dispersiva (Fig. 1A). La radiación para excitar la muestra a analizar la proveía una fuente de ${ }^{241} \mathrm{Am}$ (americio radiactivo) encapsulado en una carcasa anular, con una intensidad de 20 milicurios. Un detector de estado sólido silicio/litio recogía la radiación fluorescente en un área de $80 \mathrm{~mm}^{2}$ tras atravesar una ventana de berilio de $0,025 \mathrm{~mm}$.

La información recogida era procesada en un ordenador Kevex Unispec 7000 de Digital System LSI 11/03 con software Quantex V03B-00 Rev. 11/80 y V04/80 (las condiciones de trabajo en Rovira et al. 1997: 6-7).

Este espectrómetro usaba patrones de referencia para calcular la composición. En un principio contábamos con la colaboración del Centro Nacional de Investigaciones Metalúrgicas (CSIC) para equipar la memoria con material de referencia certificado para análisis de bronces y latones. Después se pudo adquirir con fondos del PA un número suficiente de patrones de bronce, latón y plomo a la firma BNF Metal Technology Centre de Inglaterra y a otros proveedores. La tabla 1 recoge los patrones propios actualmente utilizados por el proyecto.

Este instrumento estuvo operativo hasta julio de 1996, cuando por una avería seria se le dio de baja. Con él se analizaron las series AA y PA hasta el número PA7947 del proyecto, además de otras series cortas para otros proyectos. De su manejo se ocuparon quienes esto escriben, con una larga colaboración de Susana Consuegra en la época en que estuvo instalado en el Museo de América y en el IPHE.

A fines de 2002 el Museo Arqueológico Nacional adquirió un espectrómetro multicanal portátil Metorex $X-M E T$ 920MP por fluorescencia de rayos-X (Fig. 1B). El instrumento contaba con una fuente de excitación primaria doble de rayos gamma, proporcionados por ${ }^{109} \mathrm{Cd}$ (cadmio radiactivo) y ${ }^{241} \mathrm{Am}$ (americio radiactivo) en un montaje compacto dentro del cabezal en el que se alojaba también el detector de silicio/litio. El método de cuantificación utiliza el ajuste por mínimos cuadrados a rectas de calibración construidas con patrones certificados (condiciones de trabajo y otras características en Renzi 2013: 153-154).

$\mathrm{El}{ }^{109} \mathrm{Cd}$ es un isótopo de vida media corta $(462,6$ días) y al cabo de cinco años la intensidad de la radiación había descendido a niveles que hacían inútil esa fuente, por lo que se continuó trabajando sólo con la de ${ }^{241} \mathrm{Am}$ ante la dificultad para conseguir un recambio. De hecho el instrumento dejó de estar operativo en 2008 cuando la firma finesa Metorex fue absorbida por una compañía inglesa que interrumpió la asistencia técnica a los instrumentos Metorex. Con este espectrómetro se analizó la serie PA10000.

Consciente la Dirección del Museo Arqueológico Nacional del interés que tiene disponer de un equipo de análisis no destructivo en su laboratorio, inició el expediente administrativo para la compra de otro analizador. 


\begin{tabular}{|c|c|c|c|c|c|c|c|c|c|c|}
\hline Patrón & $\mathbf{F e}$ & $\mathbf{N i}$ & $\mathrm{Cu}$ & Zn & As & Ag & Sn & Sb & $\mathbf{P b}$ & $\mathbf{B i}$ \\
\hline 21 Blanco & 0,03 & 0,3 & 79,21 & 3,32 & & & 7,03 & 0,2 & 9,78 & \\
\hline $32 \mathrm{X}$ CAS3 & & & 96,7 & & 2,92 & & 0,36 & & & \\
\hline $32 \mathrm{X}$ SEB6 & 0,42 & 0,86 & 85,2 & 5,21 & 0,082 & & 6,74 & 0,085 & 0,083 & 0,6 \\
\hline BNFC50.01 & 0,18 & 1,79 & 75,27 & 0,85 & 0,18 & & 9,8 & 0,52 & 11,2 & \\
\hline BNFC50.02 & & & 78,62 & & & & 10,5 & & 10,8 & \\
\hline BNFC50.03 & 0,011 & 2,28 & 78,62 & 1,45 & 0,1 & & 8,5 & 0,2 & 8,7 & \\
\hline BNFC50.04 & 0,11 & 1,00 & 77,06 & 0,54 & 0,093 & & 11 & 0,4 & 9,5 & \\
\hline BNFL.04 & & & & & & & 0,43 & 0,001 & 99,45 & \\
\hline BNFL21.01 & & & 0,007 & & & 0,0048 & 0,11 & 0,0005 & 99,79 & \\
\hline BNFL21.02 & & & & & & 0,007 & 0,23 & 0,0007 & 99,72 & \\
\hline BNFL21.03 & & & & & & 0,013 & 0,34 & 0,0003 & 99,53 & \\
\hline UE10-1 & 0,31 & 0,97 & 82,7 & 0,30 & & & 14,7 & 0,36 & 0,32 & \\
\hline UE15 & 0,14 & 0,24 & 87,1 & 0,16 & 0,09 & & 10,75 & 0,61 & 0,5 & \\
\hline UE50 & 0,07 & 0,11 & 84,3 & 3,98 & & & 8 & 0,3 & 3,04 & \\
\hline UE51 & 0,23 & 0,31 & 82,25 & 4,45 & & & 7,05 & 1,66 & 3,85 & \\
\hline UE52 & 0,08 & 0,33 & 83,2 & 5,2 & & & 6,05 & 0,02 & 5,03 & \\
\hline UZ30-1 & 0,07 & 0,05 & 63,85 & 33,02 & & & 1,33 & & 1,03 & \\
\hline UZ45 & 0,13 & 1,00 & 66,95 & 30,3 & & & 0,26 & & 0,21 & \\
\hline UZ51 & 0,1 & 0,15 & 83,52 & 14,4 & 0,085 & & 1,52 & & 0,19 & \\
\hline $\mathrm{Ag} / \mathrm{Cu} / \mathrm{Pb} 2$ & & & 20,16 & & & 77,87 & & & 1,96 & \\
\hline RAgA3 & & & 8,42 & & & 91,57 & & & & \\
\hline RAgA1 & & & 2,92 & & & 97,08 & & & & \\
\hline
\end{tabular}

Tab. 1. Patrones certificados de base cobre, plomo y plata utilizados para la calibración de los espectrómetros del "Proyecto Arqueometalurgia de la Península Ibérica". Valores expresados en \% en peso.

El nuevo espectrómetro es un portátil de tipo pistola, de la firma Innov-X System Inc. (Fig. 1C) que va equipado con tubo de rayos $\mathrm{X}$ y ánodo de plata, y trabaja con voltaje de $35 \mathrm{kV}$ y corriente de $20 \mu \mathrm{A}$ con un filtro de aluminio de $2 \mathrm{~mm}$. Estos espectrómetros portátiles suelen identificarse con las siglas $p X R F$. Tras calibrar el equipo a partir del conjunto de patrones disponible se estableció una rutina de análisis de $40 \mathrm{~s}$, que se amplía a $60 \mathrm{~s}$ cuando la presencia de elementos cercanos al límite de detección lo aconseja para su correcta cuantificación. El ánodo de plata condiciona la lectura de los elementos con rangos energéticos superiores a $20 \mathrm{keV}$, especialmente la propia plata y el antimonio cuyos límites de detección se sitúan en $0,15 \%$ (1.500 ppm), muy elevados en comparación con los anteriores espectrómetros. Con este instrumento se está analizando la serie PA20000.

\subsection{Metalografía de metales}

La metalografía microscópica es una técnica que permite visualizar la estructura que forman los agregados cristalinos que constituyen la masa metálica. Está íntimamente relacionada con los procesos de taller a los que fue sometido el objeto durante su elaboración (Rovira y Gómez Ramos 2003).

El primer microscopio metalográfico utilizado por el PA fue un Reichert MeF del laboratorio del ICROA (Fig. 2A). Está equipado con dos cámaras fotográficas, una para placa de gran formato y otra para carrete de paso universal.

Más tarde, cuando se llevó a cabo la remodelación del Museo de América con vistas a su re-inauguración con motivo del V Centenario del Descubrimiento de América, se equipó el laboratorio con una línea completa 


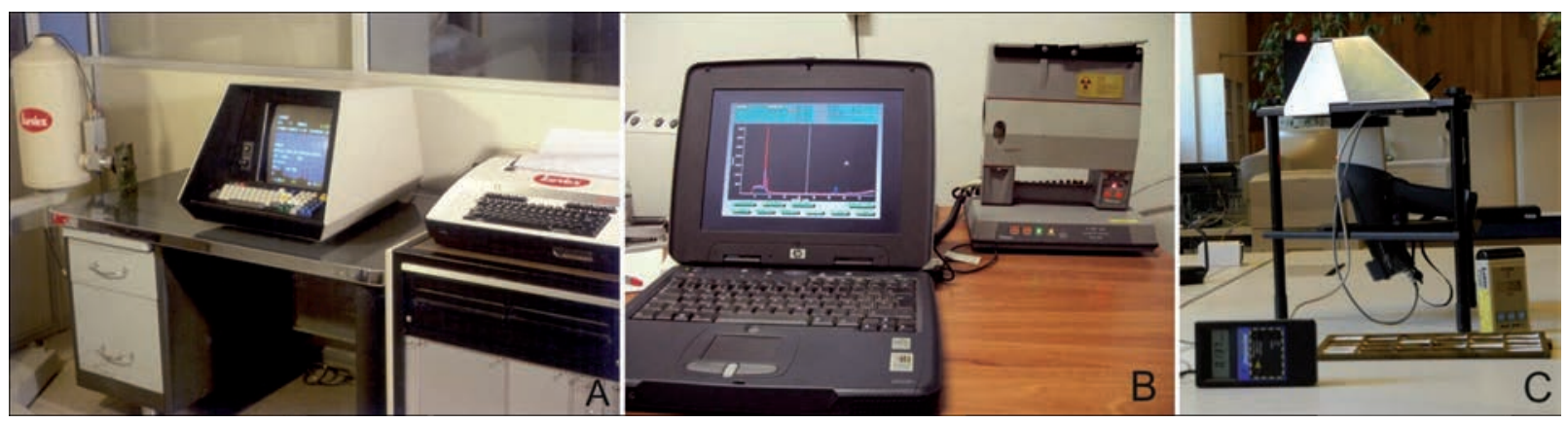

Fig. 1. Espectómetros empleados en el "Proyecto Arqueometalurgia de la Península Ibérica: A. Kevex 7000 instalado en el ICROA en 1982; B. Metorex X-MET 920 del Museo Arqueológico Nacional adquirido en 2002; C. Innov-X del Museo Arqueológico Nacional adquirido en 2009.

de microscopía óptica: microscopio biológico, microscopio estereoscópico convencional y metalográfico, este último un Reichert $M e F 3 A$ con cámaras fotográficas Leica de paso universal y de placa, además de cámara de video para pantalla de televisión externa (Fig. 2B).

Finalmente el Instituto de Historia del CSIC adquirió en 2005 para los laboratorios de $\mathrm{I}+\mathrm{D}+\mathrm{i}$ de Arqueología un microscopio convencional Leica $D M L$ con cámara digital DFC480 con el que se vienen realizando los estudios metalográficos en los últimos años (Fig. 2C).

\subsection{Microscopía electrónica de barrido (SEM)}

Cuando se decidió incorporar a las líneas de investigación del PA el estudio de escorias y otros restos de la actividad metalúrgica relacionados con la obtención de metales y aleaciones, era imprescindible disponer de un microscopio electrónico de barrido. Esto sucedió a mediados de los 1990 cuando se había abierto la
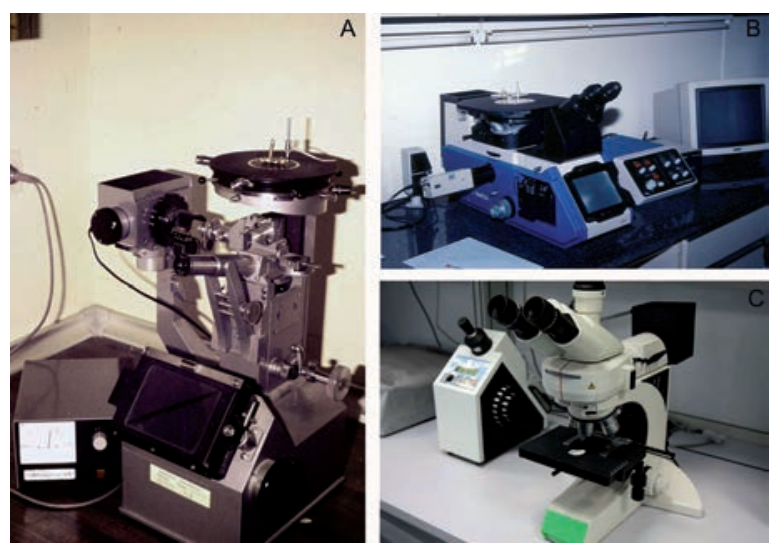

Fig. 2. Microscopios metalográficos empleados en el Proyecto Arqueometalurgia de la Península Ibérica: A. Reichert MeF del ICROA en 1982; B. Reichert MeF 3A del Museo de América en 1990; C) Leica DML del Instituto de Historia (CSIC) en 2005. posibilidad de solicitar proyectos de investigación o integrarse en otros proyectos financiados con fondos oficiales, en los cuales se incorporaban partidas para gastos de análisis. De este modo fue posible recurrir a los servicios de laboratorios externos con el equipamiento necesario y acreditada calidad.

El primero con el que iniciamos una colaboración de muchos años fue el Servicio Interdepartamental de Investigación (SIdI) de la Universidad Autónoma de Madrid. De sus excelentes instalaciones utilizamos un microscopio Philips XL30 con detectores de electrones secundarios y retrodispersados, con un analizador $D X 4 i$ de $E D A X$, operado por la microscopista Esperanza Salvador (Fig. 3A).

Más tarde recurrimos a la instrumentación del laboratorio del Museo Nacional de Ciencias Naturales (CSIC), donde disponen de un SEM ambiental FEI Quanta y un FEI Inspect operados por las microscopistas Laura Tormo y Marta Furió.

Desde 2008 el MICROLAB, Laboratorio de Microscopía, Electrónica y Microanálisis del Instituto de Historia (CSIC) tiene instalado un microscopio electrónico de barrido Hitachi 3400n Type II con microanalizador EDAX Brucker Quantax 4010, operado por el microscopista Óscar García Vuelta. Este es el equipo que utiliza el PA en los últimos años (Fig. 3B).

\subsection{Microdureza}

Estudiar la microdureza de ciertos objetos de metal muy antiguos, en particular armas e instrumentos, tiene cierto interés pues permite relacionar la calidad funcional del material con los procesos productivos. En combinación con la composición y la metalografía, sirve para extraer conclusiones sobre la idoneidad de los hábitos tecnológicos de los antiguos metalúrgicos. El PA utiliza un microdurómetro manual de mesa REMET HX1000 con variación de carga de entre 100 y $1.000 \mathrm{~g} \mathrm{y}$ un tiempo de incisión de $15 \mathrm{~s}$ que mide dureza Vickers. 

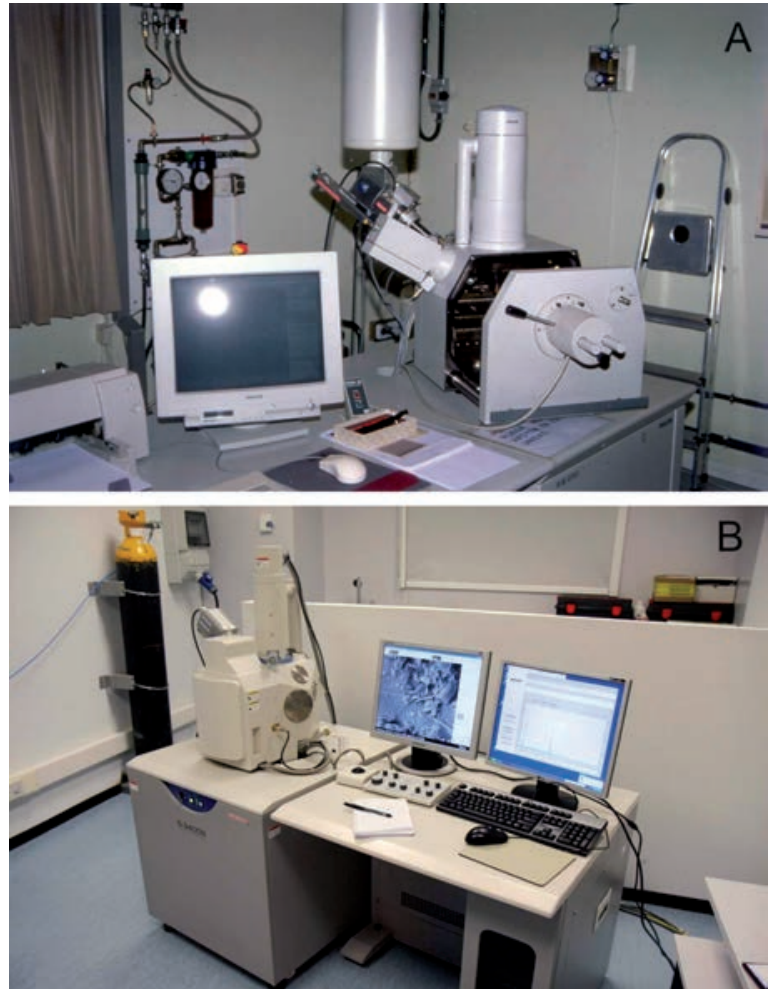

Fig. 3. A. Microscopio electrónico de barrido empleado en el Proyecto Arqueometalurgia de la Península Ibérica: A. SIdI, Universidad Autónoma de Madrid; B. MICROLAB, Instituto de Historia (CSIC).

Fue adquirido gracias a los fondos del proyecto "Caracterización tecnológica de la metalurgia del Bronce Final en la Península Ibérica" del Ministerio de Ciencia y Tecnología (BHA2001-0248). La medición se realiza sobre las probetas preparadas para metalografía y el número de medidas depende del tamaño de la muestra extraída.

\section{EL PA EN OTROS PROYECTOS}

La principal vía de financiación de la labor analítica han sido los proyectos de investigación del Plan Nacional de los diferentes Ministerios que se han encargado de sus competencias en estas últimas décadas, iniciándose con el proyecto "Arqueometalurgia de la Península Ibérica. Tecnología y cambio cultural durante la Edad del Bronce" (PB92-0315) que dirigió Manuel Fernández-Miranda y, tras su fallecimiento en 1994, Germán Delibes.

Desde 2001, y con Ignacio Montero como investigador principal, se han desarrollado los proyectos "Caracterización tecnológica de la metalurgia del Bronce Final en la Península Ibérica" (BHA2001-0248), "Caracterización analítica de la producción metalúrgica protohistórica de plata en Cataluña" (HUM2004-04861-C03-02),
"Tecnología y procedencia: plomo y plata en el I milenio AC" (HUM2007-65725-C03-02), "Relación entre materias primas locales y producción metalúrgica: Cataluña meridional como modelo de contraste" (HAR201021105-C02-02), "Circulación de cobre en el final de la Edad del Bronce del Mediterráneo occidental: Península Ibérica y Cerdeña" (HAR2014-52981-R).

También la Comunidad de Madrid subvencionó determinadas investigaciones a través de los proyectos " $\mathrm{Ca}$ libración y concordancia de análisis PIXE y XRF para el estudio de metales antiguos" (CAM 06/0154/2002), desarrollado en colaboración con el Centro de Microanálisis de Materiales (CMAN) de la Universidad Autónoma de Madrid, "Metales prehistóricos en el Instituto Valencia de Don Juan" (CAM 06/0112/2003) y "El patrimonio arqueológico y documental de la Comunidad Autónoma de Madrid: sistematización, gestión, puesta en valor y difusión desde el ámbito local al marco europeo" (CAM S2007/HUM-543).

Aunque estos proyectos han orientado la selección de materiales y periodos estudiados, al poco de comenzar la actividad e ir publicando las primeras series de análisis de la composición de metales y algunas metalografías fueron surgiendo peticiones de arqueó$\operatorname{logos}$ e instituciones para analizar nuevos hallazgos o fondos antiguos. Resultaría imposible listar aquí el gran número de colegas gracias a los cuales el PA ha llegado al punto en que se encuentra actualmente. Muchos objetos de metal y restos metalúrgicos recuperados de un gran número de excavaciones españolas de los últimos 25 años han pasado por el laboratorio del PA (Fig. 4). También ha dado soporte a la realización de numerosas tesis doctorales, no solo de sus integrantes, sino de investigadores que solicitaron datos para sus trabajos y éstos han constituido parte del cuerpo experimental de sus tesis ya sea de manera principal o accesoria (Tab. 2).

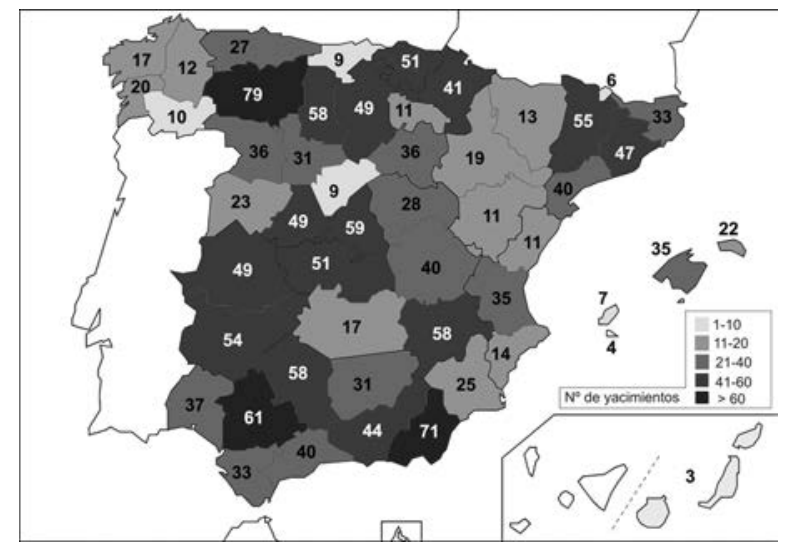

Fig. 4. Número de yacimientos, por provincias, cuyas evidencias metalúrgicas han sido estudiadas por el Proyecto Arqueometalurgia de la Península Ibérica. 


\begin{tabular}{|c|c|c|}
\hline Autor & Título Tesis, Universidad y año & Director \\
\hline Rovira Llorens, Salvador & $\begin{array}{l}\text { La metalurgia americana: Análisis tecnológico de materiales } \\
\text { prehispánicos y coloniales. Universidad Complutense de Madrid. } 1990 .\end{array}$ & Mariano Cuesta Domingo \\
\hline Montero Ruiz, Ignacio & $\begin{array}{l}\text { Estudio arqueometalúrgico en el sudeste peninsular. Universidad } \\
\text { Complutense de Madrid. } 1991 .\end{array}$ & Manuel Fernández-Mirada \\
\hline Gómez Ramos, Pablo & $\begin{array}{l}\text { La tecnología de fundición de metales en la pre y protohistoria de la } \\
\text { Península Ibérica. Universidad Autónoma de Madrid. } 1995 .\end{array}$ & $\begin{array}{l}\mathrm{M}^{\mathrm{a}} \text { del Rosario Lucas Pellicer } \\
\text { y Salvador Rovira Llorens }\end{array}$ \\
\hline Comendador Rey, Beatriz & $\begin{array}{l}\text { Los inicios de la metalurgia en el noroeste de la Península Ibérica. } \\
\text { Universidad de Santiago de Compostela. } 1997 .\end{array}$ & José M. Vázquez Varela \\
\hline Herrán Martínez, José I. & $\begin{array}{l}\text { Arqueometalurgia de la Edad del Bronce en Castilla y León. } \\
\text { Universidad de Valladolid. } 1997 .\end{array}$ & Julio Fernández Manzano \\
\hline Hunt Ortiz, Mark A. & $\begin{array}{l}\text { Minería y metalurgia prehistóricas en Andalucía Occidental. } \\
\text { Universidad de Sevilla. } 1998 .\end{array}$ & Víctor Hurtado Pérez \\
\hline Jiménez Ávila, Javier & $\begin{array}{l}\text { La toréutica orientalizante en la Península Ibérica (700-550 AC). } \\
\text { Universidad de Extremadura (Cáceres). } 1999 .\end{array}$ & Martín Almagro Gorbea \\
\hline $\begin{array}{l}\text { Rodríguez de la Esperanza, } \\
\text { María J. }\end{array}$ & $\begin{array}{l}\text { Metalurgia y metalúrgicos en el Valle del Ebro (c. 2900-1500 cal. AC). } \\
\text { Universidad Complutense de Madrid. } 2003 .\end{array}$ & Gonzalo Ruiz Zapatero \\
\hline Armada Pita, Xosé Lois & $\begin{array}{l}\text { Formas y rituales de banquete en la Hispania indoeuropea. } \\
\text { Universidade da Coruña. } 2005 .\end{array}$ & $\begin{array}{l}\text { Víctor Alonso Troncoso } \\
\text { y Ricardo Olmos Romera }\end{array}$ \\
\hline Rodríguez Bayona, Moisés & $\begin{array}{l}\text { La investigación de la actividad metalúrgica durante el III milenio A.N.E. } \\
\text { en el suroeste de la Península Ibérica. Universidad de Huelva. } 2005 .\end{array}$ & Francisco Nocete Calvo \\
\hline Morell Cortes, Nuria & $\begin{array}{l}\text { La metal.lurgia del plomo durant el període ibéric: trabll i ús del plom } \\
\text { entre els ibers del nord. Universitat Rovira i Virgili. Institut Catalá } \\
\text { d'Arqueología Clàssica. } 2009 .\end{array}$ & $\begin{array}{l}\text { Carmen Belarte e Ignacio } \\
\text { Montero Ruiz }\end{array}$ \\
\hline Soriano Llopis, Ignacio & $\begin{array}{l}\text { Producción metalúrgica prehistórica en el nordeste de la Península } \\
\text { Ibérica. Universitat Autònoma de Barcelona. } 2010\end{array}$ & Vicente Lull Santiago \\
\hline Bottaini, Carlo Emanuele & $\begin{array}{l}\text { Depósitos metálicos no Bronze Final (sécs. XIII-VII AC) do centro e } \\
\text { norte de Portugal. Aspectos sociais e arqueometalúrgicos. Universidade } \\
\text { de Coimbra. } 2012\end{array}$ & $\begin{array}{l}\text { Raquel Vilaça } \\
\text { y Claudio Giardino }\end{array}$ \\
\hline Figueroa Larre, Valentina & $\begin{array}{l}\text { Métallurgie préhispanique des sociétés du litoral Pacifique dans le Chili } \\
\text { Septentrional ( } 850 \text { apr. J.-C. }-1540 \text { apr. J.-C.). Université Paris I - } \\
\text { Panthéon Sorbonne. } 2012 .\end{array}$ & $\begin{array}{l}\text { Eric Taladoire } \\
\text { Tutores: Patrice Lecoq } \\
\text { y Benoîtt Mille }\end{array}$ \\
\hline Renzi, Martina & $\begin{array}{l}\text { La Fonteta (Guardamar del Segura, Alicante) y la metalurgia fenicia } \\
\text { de época arcaica en la Península Ibérica. Universidad Complutense de } \\
\text { Madrid. } 2012 .\end{array}$ & $\begin{array}{l}\text { Ignacio Montero Ruiz } \\
\text { Tutora: Teresa Chapa Brunet }\end{array}$ \\
\hline Murillo Barroso, Mercedes & $\begin{array}{l}\text { Producción y consumo de plata en la Península Ibérica: Un análisis } \\
\text { comparativo entre la Sociedad Argárica y los primeros asentamientos } \\
\text { Orientalizantes. Universidad de Granada. } 2013 .\end{array}$ & Ignacio Montero Ruiz \\
\hline Martínez Lázaro, Isabel & $\begin{array}{l}\text { Estudios integrados de procesos analíticos y conservativos de bronce } \\
\text { arqueológico. Aplicación a un casco montefortino y materiales afines. } \\
\text { Universitat Politècnica de València. 2016. }\end{array}$ & $\begin{array}{l}\text { Maria Teresa Doménech Carbó, } \\
\text { Antonio Doménech Carbó } \\
\text { y Salvador Rovira Llorens }\end{array}$ \\
\hline Sureda Torres, Pau & $\begin{array}{l}\text { Les comunitats prehistòriques pitiüses i la seva interacció social. } \\
\text { Aportacions des de l'arqueometal·lúrgia i els espais domèstics. } \\
\text { Universitat Pompeu i Fabra. } 2016 .\end{array}$ & $\begin{array}{l}\text { M. Eugènia Aubet Semmler } \\
\text { y Núria Rafel Fontanals }\end{array}$ \\
\hline Obón Zúñiga, Alberto & $\begin{array}{l}\text { Los inicios de la metalurgia del cobre en el Suroeste europeo. } \\
\text { Aproximación experimental a la metalurgia de Almizaraque (Almeria). } \\
\text { Universidad de Zaragoza. } 2017 .\end{array}$ & $\begin{array}{l}\text { José María Rodanés Vicente } \\
\text { e Ignacio Montero Ruiz }\end{array}$ \\
\hline Perello Mateo, Laura & $\begin{array}{l}\text { Tecnología metalúrgica del cobre y del bronce durante el periodo } \\
\text { Postalayótico en Mallorca (ca s. VI AC-S. I AC). Universitat de les } \\
\text { Illes Balears. } 2017 .\end{array}$ & $\begin{array}{l}\text { Manuel Calvo Trias } \\
\text { e Ignacio Montero Ruiz }\end{array}$ \\
\hline
\end{tabular}

Tab. 2. Tesis doctorales que se han beneficiado total o parcialmente de estudios arqueometalúrgicos realizados por el "Proyecto Arqueometalurgia de la Península Ibérica", ordenados cronológica y alfabéticamente. 
Desde comienzos de la década de 1990 los investigadores del PA se incorporaron a los equipos de investigación de otros proyectos arqueológicos nacionales e internacionales, en unas ocasiones liderándolos, en otras como colaboradores.

Destacan por su magnitud los varios proyectos dirigidos por M. ${ }^{a}$ Isabel Martínez Navarrete (CSIC), asociados al programa de excavaciones en la región minero-metalúrgica de Kargaly (Orenburgo, Federación Rusa) que encabezaba Evgeny Chernykh de la Academia de Ciencias de Rusia, cuyos resultados de orden arqueometalúrgico se publicaron en uno de los volúmenes de la monografía del proyecto ruso (Rovira 2004).

Otra colaboración de larga duración fue la surgida de dos Acciones Integradas franco-españolas dedicadas a establecer puentes tecnológicos entre la metalurgia calcolítica de Francia y de la Península Ibérica, particularmente sobre la utilización de vasijas de reducción (vasijas-horno) en ambos territorios (Rovira y Ambert 2002a, 2002b). Esto nos permitió incorporarnos a las excavaciones del poblado calcolítico de la Capitelle du Broum (Péret, Francia) para estudiar los numerosos hallazgos de escorias, minerales, restos de fundición y objetos metálicos que caracterizan la peculiar metalurgia del yacimiento (Ambert, Figueroa et al. 2009; Ambert, Balestro et al. 2013).

Un comentario especial merece la iniciativa de $\mathrm{Nu}-$ ria Rafel (Universidad de Lleida), quien propuso que iniciásemos la investigación con análisis de isótopos de plomo, a partir de 2004, con el proyecto coordinado HUM2004-04861-C03. Inicialmente orientado al plomo y la plata, posteriormente fue ampliado a los objetos de base cobre. También a Nuria Rafel, con el impulso de Fulvia Lo Schiavo, se debe el que estas investigaciones sobre la procedencia del metal se hayan extendido en los últimos años a Cerdeña y estén alcanzado una dimensión más internacional. En esta internacionalización de la investigación está influyendo el papel que se asigna tanto al cobre, como a la plata y al estaño de la Península Ibérica en el comercio y movimiento de metales durante la Prehistoria.

\section{EL PROYECTO EN CIFRAS}

\subsection{Análisis elemental $X R F$}

Los ejercicios de cuantificación pueden ser fáciles cuando la información está ordenada en una base de datos, sin embargo hay lecturas distintas sobre qué es lo que se cuantifica. Las cifras que se recogen en las tablas 3 y 4 representan el volumen total de análisis efectuados, valor que no equivale al número de objetos estudiados. En estas cifras globales, quedan incluidos los análisis del mismo objeto con espectrómetros diferentes, objetos grandes como las hachas de talón o complejos como las fíbulas, que tienen dos o más análisis, y los análisis de pátinas realizados para valorar el efecto de éstas en los resultados de la composición del metal obtenidos con una técnica de análisis superficial. En estas cifras no están incluidos los análisis a objetos restaurados en el IPHE o los del departamento de Conservación del Museo Arqueológico Nacional. Tampoco se han incorporado los metales americanos (cerca de 1.000 análisis), en gran parte publicados en la tesis doctoral de Salvador Rovira y en otras publicaciones (Rovira 1990, 1994). Los materiales extranjeros se refieren a los estudiados en los proyectos de colaboración con Rusia, Francia, Italia, Marruecos, Hungría e Irlanda.

\begin{tabular}{|c|c|c|c|}
\cline { 2 - 4 } \multicolumn{1}{c|}{} & XRF & Metalografía & LIA \\
\hline Base $\mathrm{Cu}$ & 12.353 & 714 & 319 \\
\hline $\mathrm{Au}-\mathrm{Ag}$ & 1.775 & 24 & 35 \\
\hline $\mathrm{Pb}$ & 308 & 0 & 53 \\
\hline $\mathrm{Fe}$ & 134 & 6 & 0 \\
\hline Monedas & 3.756 & 4 & 42 \\
\hline Restos metalúrgicos & 2.060 & 121 & 61 \\
\hline Minerales & 2.380 & 9 & 220 \\
\hline Extranjeros & 1.156 & 17 & 78 \\
\hline TOTAL & 23.922 & 895 & 808 \\
\hline
\end{tabular}

Tab. 3. Cuantificación por materiales de los análisis realizados por el "Proyecto Arqueometalurgía de la Península Ibérica" en el periodo 1982-2017. XRF (análisis elemental por espectrometría de fluorescencia de rayos $\mathrm{X}$ ), LIA (análisis de isótopos de plomo).

Los datos pueden descomponerse a nivel geográfico y cronológico. Desde el primero de ellos es posible afirmar que el objetivo inicial del PA de cubrir todas las provincias españolas se ha conseguido, aunque de manera desigual (Figs. 5A y B). La información de Portugal es limitada y aunque representada de manera uniforme en el mapa, procede mayoritariamente de los distritos del Norte; se debe sobre todo a la colaboración con Raquel Vilaça (Universidade de Coimbra) y Ana Bettencourt (Universidade do Minho). Las Islas Canarias, no incluidas en estas figuras, también han recibido atención por parte del PA gracias a los recientes estudios sobre Cueva Pintada de Galdar en Gran Canaria (Gutiérrez-Neira et al. 2014) y el yacimiento romano del islote de Los Lobos en Fuerteventura, bajo la dirección de Carmen del Arco Aguilar.

En la figura 5 se representa la densidad por $\mathrm{km}^{2}$ de los objetos de base cobre y de los objetos de oro y plata analizados de todos los periodos históricos. La mayor 


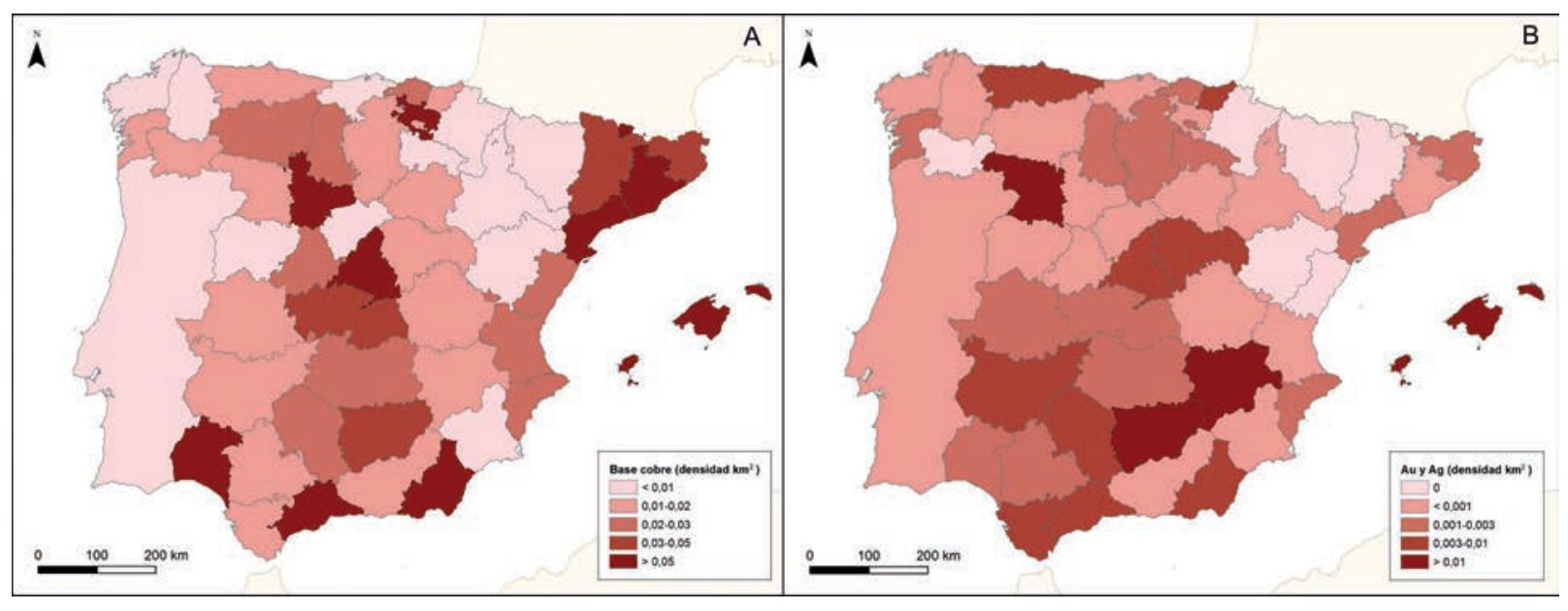

Fig. 5. Densidad por provincias $\left(\mathrm{n}^{\mathrm{o}}\right.$ de objetos $\left./ \mathrm{Km}^{2}\right)$ de objetos analizados por $X R F$ en el "Proyecto de Arqueometalurgia de la Península Ibérica": A. de base cobre; B. de oro y plata. Mapas elaborados por Antonio Uriarte (LABTEL-CSIC).

intensidad en algunas provincias obedece a circunstancias diversas. Así, en el mapa de los objetos de base cobre (Fig. 5A) la provincia de Huelva aparece destacada debido a las cerca de 400 piezas analizadas del depósito de la Ría de Huelva y la de Valladolid porque se pudo analizar el conjunto de metales de la necrópolis de Padilla de Duero. Madrid está entre las provincias con más material estudiado por efectos acumulativos de la investigación en varios yacimientos de la Comunidad donde tiene la sede el laboratorio. Si nos fijamos en el mapa de los metales nobles (Fig. 5B) sobresalen la provincia de Zamora por los materiales analizados para el estudio del tesoro de Arrabalde y las de Jaén y Albacete con depósitos de plata de época ibérica.
Desde el punto de vista cronológico (Tab. 4), no se puede negar el interés mantenido hacia la primera metalurgia, reflejado en las cifras de objetos, restos metalúrgicos y minerales que superan los 4000 análisis y que duplican los recopilados y publicados en el primer volumen del proyecto Las Primeras etapas del metal en la Península Ibérica (Rovira et al. 1997). Hasta época romana se ha conseguido un número de datos relativamente similar en objetos de base cobre. El periodo medieval sin duda está aún poco representado y debe ser reforzado en el futuro.

En el apartado de las monedas destacan las acuñaciones prerromanas, en especial de plata, y se incluye en época moderna/contemporánea el análisis de las

\begin{tabular}{|c|c|c|c|c|c|c|c|}
\hline TOTAL & Base Cu & Au-Ag & Pb & Monedas & $\begin{array}{c}\text { Restos } \\
\text { metalúrgicos }\end{array}$ & Minerales & Total \\
\hline CAL-BM & 2.684 & 241 & 1 & & 775 & 437 & $\mathbf{4 . 1 3 8}$ \\
\hline BF & 2.577 & 85 & 0 & & 196 & 32 & $\mathbf{2 . 8 9 0}$ \\
\hline H1 & 2.032 & 167 & 99 & & 382 & 57 & $\mathbf{2 . 7 3 7}$ \\
\hline H2 & 2.708 & 1.107 & 129 & 1.371 & 379 & 57 & $\mathbf{5 . 7 5 1}$ \\
\hline ROM & 982 & 48 & 64 & 512 & 91 & 3 & $\mathbf{1 . 7 0 0}$ \\
\hline VIS & 438 & 54 & 4 & 112 & 10 & 0 & $\mathbf{6 1 8}$ \\
\hline MED & 319 & 27 & 6 & 677 & 9 & 0 & $\mathbf{1 . 0 3 8}$ \\
\hline MOD-CONT & 110 & 12 & 3 & 984 & 48 & 0 & $\mathbf{1 . 1 5 7}$ \\
\hline Total & $\mathbf{1 1 . 8 5 0}$ & $\mathbf{1 . 7 4 1}$ & $\mathbf{3 0 6}$ & $\mathbf{3 . 6 5 6}$ & $\mathbf{1 . 8 9 0}$ & $\mathbf{5 8 6}$ & $\mathbf{2 0 . 0 2 9}$ \\
\hline
\end{tabular}

Tab. 4. Cuantificación por periodos cronológicos de los análisis elementales realizados por el "Proyecto Arqueometalurgia de la Península Ibérica" entre 1982 y 2017 a materiales de la Península Ibérica por XRF. Cal-BM (Calcolítico al Bronce Medio), BF (Bronce Final), H1 (I Edad del Hierro), H2 (II Edad del Hierro), ROM (Romano), VIS (Visigodo), MED (Medieval), MOD-CONT (Época Moderna y Contemporánea). 
monedas de oro y algunas de plata de la fragata Nuestra Señora de las Mercedes (Gutiérrez Neira et al. 2016).

\subsection{Microscopía electrónica de barrido}

Desde que se incorporó la microscopía electrónica de barrido a la rutina analítica se han analizado materiales de un total de 229 yacimientos, en su mayoría españoles pero también algunos foráneos mediante el establecimiento de convenios o proyectos comunes. Se ha utilizado sobre todo para el análisis de escorias, minerales y otros residuos de la metalurgia primaria, aunque también de las secciones de algunos objetos metálicos para estudiar detalladamente cuestiones microestructurales. El gráfico de la figura 6 refleja la distribución por periodos de los yacimientos. La categoría de los indeterminados (32 lugares) requiere explicación aparte. Se refiere en su mayor parte a muestras de escoriales probablemente antiguos, pero a los que no es posible asignar por el momento una cronología concreta, y a minerales de minas próximas a los yacimientos arqueológicos, explotadas hasta tiempos recientes.

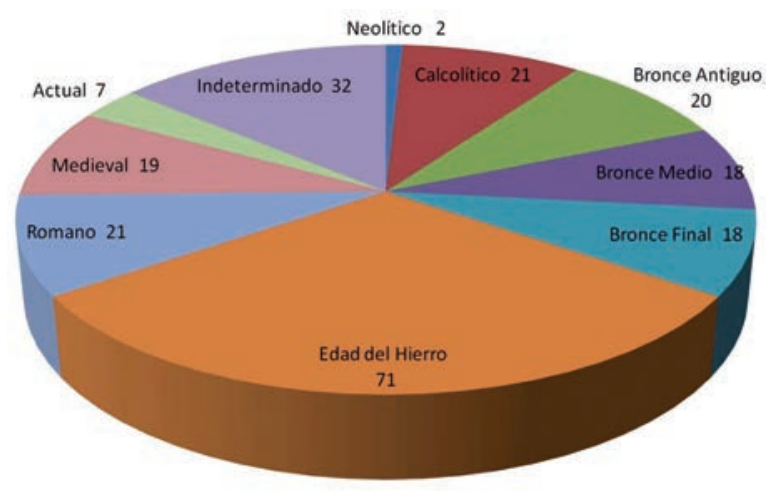

Fig. 6. Número de yacimientos de la Península Ibérica con restos metalúrgicos analizados por microscopía electrónica de barrido, distribuidos por periodos (en color en la edición electrónica).

\subsection{Metalografías}

Una parte importante en el desarrollo del PA desde sus inicios fue el uso de la metalografía óptica para conocer la tecnología de fabricación de las piezas. La publicación del tercer volumen de la serie Las primeras etapas metalúrgicas de la Península Ibérica (Rovira y Gómez Ramos 2003) representa el corpus más numeroso disponible y la primera síntesis global sobre el Calcolítico y la Edad del Bronce, pero además diversas publicaciones previas recogían la investigación en materiales de la Edad del Hierro. Actualmente contamos con casi 900 objetos metalografiados, en su mayoría de base cobre, aunque también se han estudiado de hierro y de plata.

\subsection{Isótopos de plomo}

A partir de los proyectos iniciados en 2004 sobre la producción de plata en Cataluña se incorporó a la investigación este tipo de análisis. Gran parte de los resultados procede del laboratorio del Servicio de Geocronología y Geoquímica Isotópica de la Universidad del País Vasco, pero se han solicitado asimismo análisis a los laboratorios de la Universidad Goethe de Frankfurt y al Centro para Arqueometría Curt Engelhorn de Mannhein. Siempre se han utilizado las técnicas disponibles más precisas (TIMS y $M C-I C P-M S$ ).

La investigación se ha enfocado por un lado a los propios restos arqueológicos, pero ha tenido un papel fundamental para las interpretaciones el análisis de los minerales recogidos directamente en las minas (200 muestras). Disponemos de otros 800 análisis de materiales arqueológicos, la mayoría de los cuales cuentan con análisis elemental realizado por $X R F$ en el PA. Además otro conjunto, en especial monedas, ciertos objetos de plata o materiales estudiados durante el periodo cuando no disponíamos de un equipo de $X R F$, han sido analizados o bien por microscopia electrónica de barrido (SEM) o por PIXE. Sobre el estado de la cuestión de los estudios de procedencia con isótopos de plomo y el papel desempeñado por el PA puede consultarse el trabajo de Montero Ruiz (2018).

\section{LA VALIDEZ DE LOS ANÁLISIS}

Los análisis efectuados por microscopía electrónica de barrido ofrecen la fiabilidad y margen de error derivados de la interpretación de los resultados. Los datos objetivos en sí no ofrecen dudas pues han sido obtenidos con equipos de laboratorios altamente cualificados según la actual normativa de calidad. Los estudios metalográficos, efectuados enteramente en nuestro laboratorio, están sujetos al mismo posible error de una interpretación errónea de las microestructuras. Esto es poco probable porque en general existe un número limitado de posibilidades y una abundante bibliografía comparativa. Solo algunos detalles microestructurales, por su rareza, pueden resultar dudosos o sujetos a la interpretación discutible del analista. Pero las microestructuras básicas se identifican fácilmente.

Los análisis de la composición de los metales por espectrometría de fluorescencia de rayos-X por energías dispersivas $(X R F-E D)$ sí requieren una discusión previa más extensa. Como es sabido, esta técnica analiza la 
superficie del objeto, arrancando información hasta una profundidad de unas pocas decenas de micrómetros, dependiendo esto principalmente de la intensidad de la radiación excitante y del camino que sigue la radiación fluorescente hasta el detector. En teoría la superficie de la muestra ha de ser perfectamente plana y tapar por completo la ventana radiante para que la radiación emergente lo haga según un mismo ángulo y con un mismo recorrido (Hall et al. 1973). Ello difícilmente sucede en una pieza arqueológica cuando se analiza una superficie grande, como es el caso de las ventanas radiantes de los espectrómetros Kevex (25 mm de diámetro) y Metorex (20 $\mathrm{mm}$ de diámetro) del PA. En el espectrómetro Innov- $X$ este problema es prácticamente insignificante porque el diámetro del haz es más pequeño, de orden milimétrico. Sin embargo, en la práctica, los efectos de distancia y tamaño se pueden minimizar en gran medida utilizando la rutina de cuantificación apropiada dentro de las posibilidades del software suministrado con cada espectrómetro.

En Rovira (1990: 92-110) se expone en detalle el trabajo experimental previo efectuado con el espectrómetro Kevex en 1982 para decidir cuál era el procedimiento más preciso en el cálculo de la composición del metal, que incluía pruebas de repetitividad de resultados y otras rutinas habituales. Para establecer los resultados utiliza patrones de referencia certificados. De las pruebas efectuadas resultaba que los errores en las determinaciones eran inferiores a los que se tienen como norma (menor del $5 \%$ en elementos mayoritarios y menor del $50 \%$ en minoritarios).

Aprovechando la larga experiencia adquirida con el Kevex fue sencillo poner a punto el espectrómetro Metorex.

Finalmente, el espectrómetro Innov- $X$, utilizado desde 2009, calcula las concentraciones con un método basado en patrones internos similar al desarrollado para las microsondas de los microscopios electrónicos. Esto simplifica enormemente el análisis al no depender de un conjunto de patrones externos, al tiempo que las calibraciones propias son fruto de desarrollos realizados por el fabricante para dotar al producto de unas características dentro de los estándares propios de esta técnica analítica. Estas calibraciones de fábrica fueron ajustadas con el conjunto de patrones disponible para una mejor cuantificación de los resultados. Tiene otras ventajas en comparación con los equipos empleados con anterioridad, siendo una de ellas la posibilidad de ampliar el número de elementos químicos analizables a elementos ligeros con número atómico inferior a 20 (calcio).

Sin embargo, los problemas inherentes al análisis de objetos metálicos no provienen de los instrumentos utilizados, que ya hemos visto que resultan adecuados a los fines propuestos. Los problemas derivan sobre todo de que, al tratarse de un análisis de la superficie, las transformaciones ocurridas en ella alteran muy significativamente los valores del material original. En pocas palabras: la corrosión metálica crea una capa superficial de compuestos (pátina) en la que encontraremos todos los elementos químicos del metal sano pero con relaciones ponderales muy distintas a las de dicho metal. Sobre este problema ya llamó la atención Hall (1960) cuando comenzó a aplicarse la fluorescencia de rayos$\mathrm{X}$ a metales arqueológicos, subrayando la importancia de efectuar una cuidadosa limpieza de la superficie del objeto para eliminarle todos los productos de corrosión y descubrir el metal sano. La limpieza es un proceso agresivo que no siempre hemos podido aplicar, sobre todo en objetos de las colecciones de museos, ante la negativa de los responsables al cargo a que se interviniera sobre ellos. En esos casos el análisis tiene sobre todo valor cualitativo (qué elementos químicos hay en el metal) pero los porcentajes corresponden a la composición de los productos de alteración. En la ficha correspondiente se anota esa circunstancia. Por suerte la mayoría de las veces pudimos limpiar el área a analizar, mediante chorro de arena, lijas abrasivas y fresas de carborundo aplicadas con micromotor.

No son pocas las piezas que por su gran antigüedad o por la gravedad del ataque de la corrosión apenas conservan núcleo metálico. Poco se puede hacer entonces salvo determinar la composición del material residual y extraer una idea cualitativa.

Existe abundante bibliografía sobre el fenómeno de enriquecimiento superficial de la mayoría de elementos químicos en las pátinas. Para las aleaciones de base cobre es importante conocer el comportamiento del estaño y del plomo. En ambos casos se producen grandes desviaciones según se analice la pátina o el metal sano. En la figura 7A se representa una serie de análisis efectuados con y sin pátina a objetos de bronce.

Como era de esperar, los porcentajes de estaño en los productos de corrosión suelen ser mucho mayores que en el metal limpio ${ }^{2}$. Se da, además, un comportamiento errático manifestado por una recta de regresión con un valor $\mathrm{R}^{2}$ propio de una correlación baja. Utilizar la ecuación para recalcular los valores no serviría para aproximarnos al valor real. Probablemente el espesor y la porosidad de la capa de corrosión sean variables de gran influencia en el fenómeno que observamos. La conclusión debe ser que en los bronces donde la cifra obtenida en la pátina supera ampliamente el $15 \%$ de estaño, la composición hallada debe tomarse con reservas y el análisis considerarse de carácter cualitativo. En un reciente trabajo experimental se ha calculado que la

\footnotetext{
${ }^{2}$ Hemos detectado que en determinadas áreas (especialmente en Baleares) o en yacimientos próximos al mar, las cantidades de estaño en la pátina son inferiores a las del núcleo metálico. Este es un fenómeno que debe ser investigado con mayor detalle.
} 


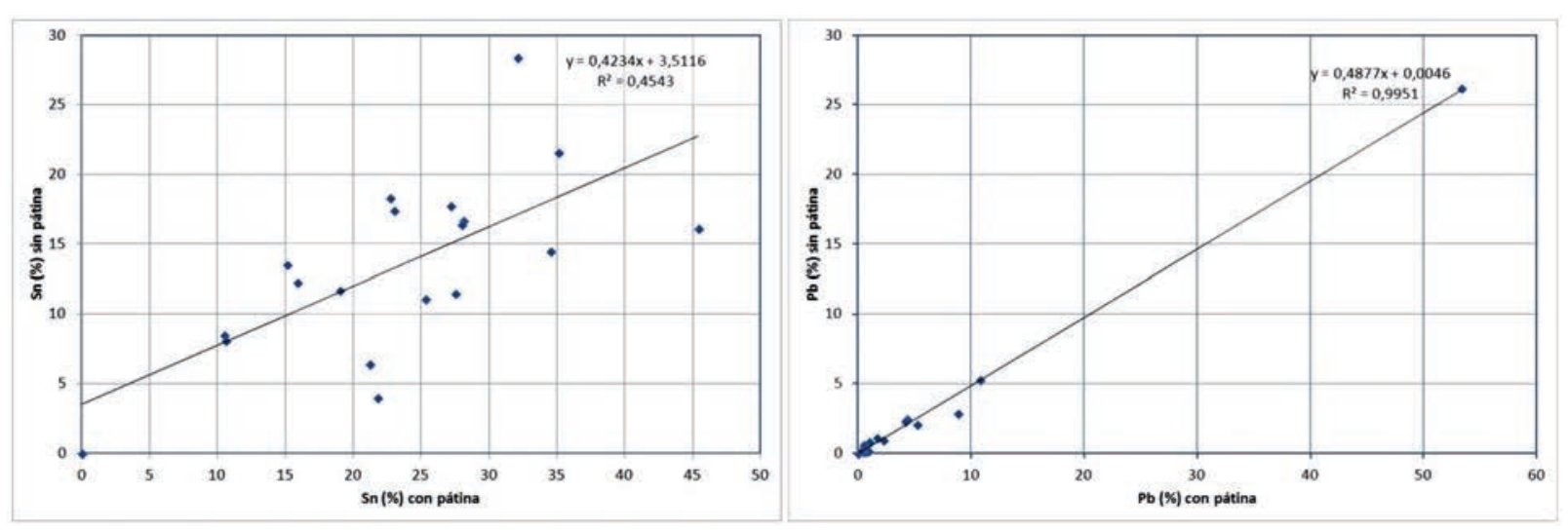

Fig. 7. Dispersión de los pares de valores en un objeto analizado con su pátina y sin ella: A. de estaño (obsérvese la escasa correlación entre ellos); B. plomo (la correlación es buena).

desviación entre el valor medio del estaño en la pátina y en el metal aparentemente sano tras la limpieza de la pátina, en un conjunto de 41 muestras analizadas por $p X R F$, es muy grande, del orden del $55 \%$ (Orfanou y Rehren 2015: 391, tab. 4); en nuestro caso la desviación es todavía mayor, del orden de $74 \%$, lo cual justifica nuestra llamada a tomar con reserva resultados con altos tenores de estaño en la pátina. De esta limitación también nos hablaban ciertas piezas metalografiadas cuya microestructura no se correspondía con la de una aleación con mucho estaño. En Rovira y Gómez (2003: 49-50), p. ej., ya hablábamos de la influencia de la corrosión intergranular en el resultado del análisis de un metal aparentemente limpio, hecho que también justifican Orfanou y Rehren (2015: 392).

En cualquier caso, la serie de análisis PA20000 efectuada con el espectrómetro $p X R F$ Innov- $X$, para la que sistemáticamente se elimina al máximo la corrosión superficial, concuerda bien con los resultados obtenidos con equipos de mayor precisión (Orfanou y Rehren 2015; Asinelli y Martinón-Torres 2016).

En cambio con el plomo el comportamiento es diferente, aunque también hay más plomo en la superficie oxidada. La correlación entre valores en la pátina y en el metal sano es excelente (Fig. 7B) e invitaría a utilizar la ecuación para recalcular concentraciones. Sin embargo es más que probable que nos hallemos ante una excepción derivada del conjunto de objetos aquí analizados, porque la experiencia de otros investigadores es que el plomo se comporta de manera similar al estaño (Orfanou y Rehren 2015: 392). Según estos autores, la desviación de medias de su conjunto de análisis es del $204 \%$ y en nuestro caso del $96 \%$, menor pero exageradamente elevada, lo cual indica un fuerte enriquecimiento en plomo de las pátinas.

La importancia del cobre arsenical entre las aleaciones metálicas de las primeras etapas metalúrgicas hace del arsénico otro elemento químico al que hay que prestar especial atención. Su enriquecimiento en la pátina sigue un modelo intermedio entre el estaño y el plomo. En el PA hubo un problema añadido: no disponíamos al principio de buenos patrones certificados con porcentajes superiores a $0,5 \%$ As, ni posibilidades económicas para comprarlos. Para suplir esta carencia utilizamos un par de objetos arqueológicos en los que los picos de arsénico en el espectro hacían presumir porcentajes de arsénico altos y los evaluamos por el método de ajuste por mínimos cuadrados del Kevex, presuponiendo que la interpolación produciría resultados aprovechables. Cuando comenzamos a utilizar el espectrómetro Metorex, resultó que no era así: los tenores de arsénico en los análisis de las series AA y la serie inicial de PA (hasta PA7947) están infravalorados en límites que exceden el $5 \%$ de error admitido para elementos mayoritarios. Para el Metorex ya disponíamos de mejores patrones de arsénico. Con todo, hasta que no hemos trabajado con el Innov-X no hemos podido valorar con precisión suficiente los errores anteriores. Para ello se han reanalizado varios objetos con el nuevo espectrómetro calculando las desviaciones de los resultados. La figura $8 \mathrm{~A}$ y $\mathrm{B}$ expone gráficamente los resultados a partir de los cuales, con una hoja de cálculo, se pueden reconvertir los contenidos de arsénico de análisis antiguos y recalcular completamente el resto de elementos del análisis por un sencillo cálculo aritmético de reparto proporcional, que es el que habitualmente se usa para ajustar los porcentajes para sumar 100 .

Para análisis de metales preciosos no teníamos patrones certificados. Adquirir patrones de oro de más de $25 \mathrm{~mm}$ de diámetro estaba fuera de las posibilidades de un proyecto siempre escaso de financiación directa. La cuestión se resolvió recurriendo a chapas laminadas de las usadas en joyería, certificadas por la 

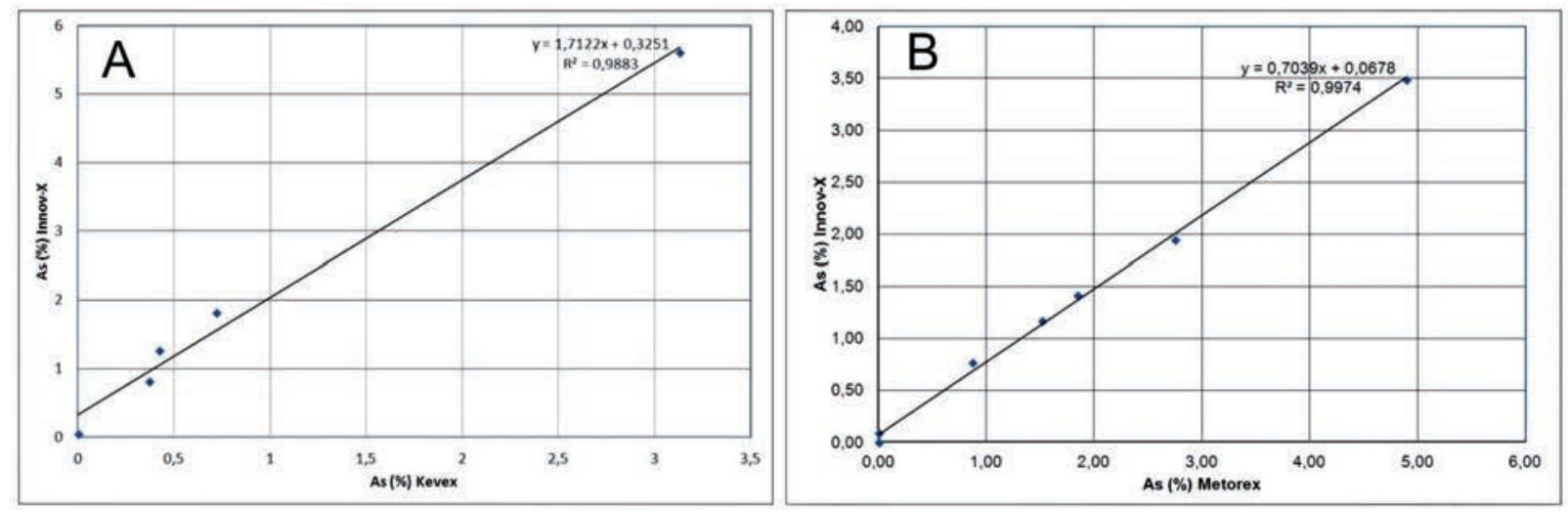

Fig. 8. Correlación de los porcentajes de arsénico determinados en un mismo objeto con los espectrómetros: A. Kevex e Innov-X; B. Metorex e Innov-X.

Sociedad Española de Metales Preciosos, y a algunos objetos arqueológicos, analizados con la microsonda del microscopio electrónico de barrido y otros métodos. En la época Metorex se compraron tres patrones de aleaciones de plata.

\subsection{Las comparaciones con el proyecto $S A M$}

La comparación de resultados obtenidos con distintas técnicas o en diferentes laboratorios ha sido una preocupación constante de la investigación arqueometalúrgica, y en especial a partir de la generalización de las técnicas no destructivas de análisis superficial en la década de 1970. Tanto los efectos de la pátina como las tendencias a depleciones o enriquecimientos superficiales han generado dudas sobre la validez de estos datos, pero también las calibraciones empleadas para el cálculo de las composiciones pueden alterar los valores que se obtienen con técnicas no superficiales. Algunos intentos comparativos han demostrado que los resultados pueden ser suficientemente distintos (p. ej. Northover y Rychner 1998) o incluso poco compatibles en cuanto a los proporciones de los elementos mayoritarios cuando los laboratorios no cuantifican usando parámetros fundamentales calibrados con estándares (Heginbotham et al. 2010), práctica que al parecer es más frecuente de lo que pensábamos.

La serie del $S A M$ ha sido un referente para todos los estudios europeos y existen valoraciones muy diversas a la hora de comparar sus resultados. Así, Chernykh (1978) comentaba las diferencias de los 78 objetos en común entre el laboratorio de Moscú (OES) y el $S A M$ $(O E S)$ y, a pesar de la concordancia en los porcentajes de estaño de los bronces, el resto de elementos presentaba notables diferencias, especialmente en plomo y níquel. En el estudio del oro, Warner y Cahill (2011) señalaban las discrepancias en los contenidos de plata en los objetos reanalizados del Museo Nacional de Irlanda, aunque hay que valorar los problemas de los análisis en superficie. A pesar de haber sido cuestionados los resultados, la mayoría de los autores reivindica su validez y utilidad, aunque no así el tratamiento o los modelos estadísticos empleados para asignar grupos de metales (Pollard y Bray 2014: 233). Como señala Pernicka (2014: 245): "it rather turns out that especially the large analytical programs in Stuttgart and Moscow produced essentially accurate analyses but with low precision of about $30 \%$ relative (Fig. 11.2), while modern methods usually range between 2 and $5 \%$ ".

El PA comparte al menos 73 piezas analizadas con seguridad también por el SAM (62 cobres y 11 bronces). Hay más piezas que han sido analizadas por ambos laboratorios pero no podemos identificarlas con exactitud al carecer las publicadas en el $S A M$ de número de inventario o, en ausencia de dibujo, de la descripción de algún rasgo tipológico que las diferencie de piezas similares. Es el caso de las hachas planas de Valchica (Ejea de los Caballeros), de las que 9 fueron analizadas en el SAM (7630-7638), pero solo 6 en el PA. No podemos comparar individualmente los análisis al no estar identificadas en el $S A M$ con el número de inventario y solo una estar dibujada, pero se observa una buena coincidencia ya que los contenidos de arsénico oscilan entre $0,54 \%$ y $1,6 \%$ en la serie del $S A M$ y entre $0,82 \%$ y $1,66 \%$ en los análisis del PA realizados con el espectrómetro Innov- $X$. El resto de elementos es minoritario (menos del 0,1 \% en ambas series). Solo en un análisis de cada serie se detecta una cantidad alta de antimonio, por lo que quizás esta coincidencia podría servir de criterio para determinar que son la misma pieza.

Ejemplo de la complejidad de comparar resultados pieza a pieza por cambios en la identificación del propio 
museo es el tesoro de Montilla, que contenía además de una diadema de oro y un puñal de lengüeta, cuatro puntas Palmela. El SAM publicó el análisis de cinco puntas Palmela ( $\left.n^{\circ} 1000-1004\right)$ con esta procedencia sin número de inventario y con dibujos para la identificación condicionados por la similitud formal de tres de ellas. La quinta Palmela ahora sabemos que procede de Segovia (Rovira y Port 2012-2013) y corresponde a la n 1004.

Cuando existen discrepancias notables en el resultado de un objeto quizás debamos considerar que hay un error de transcripción en los datos o que se trata de otra pieza distinta. En la comparación de los análisis de las dos hachas planas de Instituto Valencia de Don Juan (Tab. 5) podemos observar que, aunque no podemos identificar a cual corresponde cada uno de los análisis al faltar en la publicación del $S A M$ el número de inventario y el dibujo, los resultados de una de ellas son completamente contradictorios. Los análisis del PA presentan dos hachas con similares características que destacan por su elevado contenido en antimonio. En cambio en uno de los análisis $S A M$ el antimonio no es detectado y también difiere en la proporción de plata. Al no incluir el $S A M$ el porcentaje de cobre resulta difícil identificar errores de transcripción, que a veces pueden detectarse al sumar todos los elementos presentes. También son posibles otro tipo de errores que se producen en el manejo manual de grandes bloques de información.

\begin{tabular}{|c|c|c|c|c|c|}
\hline $\mathbf{N}^{\mathbf{o}}$ Análisis & $\mathbf{C u}$ & As & Ag & Sn & Sb \\
\hline PA11237 & 94,6 & 0,89 & 0,24 & 0,05 & 3,80 \\
\hline PA11244 & 96,3 & 0,76 & 0,21 & 0 & 2,34 \\
\hline SAM1043 & - & 0,53 & 0,013 & 0 & 0 \\
\hline SAM1044 & - & 0,84 & 0,19 & 0 & 1,55 \\
\hline
\end{tabular}

Tab. 5. Comparación de los análisis realizados por el Studien zu den Anfängen der Metallurgie (SAM) y el "Proyecto Arqueometalurgia de la Península Ibérica" (PA) de las dos hachas planas del Instituto Valencia de Don Juan (Madrid) procedentes de Manganeses de la Polvorosa (Zamora).

El ejemplo de error de mayor transcendencia ha sido la punta de lanza de San Esteban de Río Sil (Montero Ruiz et al. 2016) en el que el análisis publicado por el $S A M$ identifica la pieza como cobre, mientras que el PA indica que es un bronce rico en estaño. Sobre esta pieza existen numerosas cuestiones dudosas y que no encajan en la descripción publicada en el $S A M$, que la identifica como un fragmento de espada (Schwert, fragm.) procedente del Salto de San Esteban, perteneciente a la colección del Museo Municipal de Madrid (Junghans et al. 1968: $n^{\circ}$ 1038) y tampoco se incluye su dibujo en las láminas. Todo ello sugiere un posible error en la identificación de ese análisis en la base de datos del proyecto $S A M$. La primera publicación (Almagro Basch 1958: 25) indicaba que "no ha podido aún ser analizado su metal" pero se presentaban los análisis de las otras tres piezas aparecidas en conjunto, todas de bronce. El análisis de la punta de lanza a cargo del $S A M$ aparece por primera vez en Inventaria Archaeologica (Almagro Basch 1960) y es reproducido por todos los autores en publicaciones posteriores destacándose la excepcionalidad de su composición de cobre sin alear. En el conjunto de San Esteban de Río Sil no hay ninguna otra pieza que pueda identificarse como fragmento de espada.

Teniendo en cuenta estas circunstancias de difícil identificación, la figura 9A solo muestra los resultados comparativos del arsénico entre los análisis del $S A M$ y los que creemos corresponden a las mismas piezas analizadas por los diferentes espectrómetros empleados en el PA. Esta comparativa sigue la propuesta de Pernicka (1990) con una representación en escala logarítmica donde la línea diagonal central indica la concordancia perfecta, mientras las líneas laterales marcan el margen superior e inferior para considerar los resultados aceptables. A pesar de la tendencia a infravalorar el arsénico con el Kevex, la distribución muestra valores a ambos lados de la línea central señalando unas diferencias aleatorias y no sistemáticas que deben obedecer a circunstancias individuales y no a un problema o tendencia analítica específica. Los análisis con el Metorex y el Innov- $X$ se distribuyen más próximos a la línea central y reflejan una mejor concordancia de valores. En la comparación que Pernicka realizó (1990, 2014) entre los análisis del $S A M$ y de otros laboratorios se observa cómo, aunque la tendencia general es correcta, siempre aparecen casos fuera de los márgenes fijados. Estas divergencias individuales, en todos los elementos y no solo en el arsénico, deben ser relativizadas por las propias condiciones tecnológicas de la metalurgia prehistórica en las que la heterogeneidad del metal es una de las principales características. Aceptamos que la muestra tomada de un objeto o el análisis en una parte de su superficie representa la composición del objeto, pero hay factores como el proceso de enfriamiento del metal que generan una distribución no homogénea de inclusiones o segregados, que puede ser mayor o menor dependiendo de cada uno de los elementos y de su mayor o menor proporción en el metal. Análisis en zonas distintas de la superficie o del interior pueden variar en sus resultados con la misma técnica de análisis. Para ilustrar esta situación tomamos como ejemplo los análisis de masas de metal de varios cientos de gramos (equivalentes por ejemplo a las hachas) realizados en Shar-i-Shokhta (Irán) y fechados en el III milenio cal AC (cf. Hauptmann et al. 2003: tab. 4). Las muestras tomadas del interior mediante perforación en diferentes

Trab. Prehist., 75, N. ${ }^{\circ}$ 2, julio-diciembre 2018, pp. 223-247, ISSN: 0082-5638

https://doi.org/10.3989/tp.2018.12213 
puntos se representan en la figura 9B seleccionando los valores extremos de arsénico en la misma pieza y ejemplifican cómo podemos estar fuera de los márgenes de compatibilidad de resultados en una misma pieza, tal y como sucede en la comparación entre laboratorios. Los análisis realizados con toma de muestra en el $S A M$ y en superficies limpias del metal por el PA fueron siempre en partes o zonas distintas de la pieza.

Como dato curioso tenemos un solo objeto con análisis realizados por el $S A M$ y los 3 espectrómetros del PA (Tab. 6).

\section{LOS RESULTADOS DEL PROYECTO}

Cuantificar en detalle las aportaciones al conocimiento de la tecnología metalúrgica habidas a lo largo de los más de 35 años de desarrollo del PA es tarea que escapa al enfoque de este trabajo. Han sido más de 300 publicaciones en revistas especializadas, capítulos de libros y actas de reuniones científicas (con un número elevado en foros internacionales), a las que hay que sumar las tesis doctorales cuyos datos experimentales fueron proporcionados por o se obtuvieron en el laboratorio del PA (Tab. 2). Tampoco podemos dejar de mencionar los muchos especialistas formados mediante becas, estancias u otras fórmulas de asociación.

La primera serie de análisis publicada (Rovira et al. 1997), referida a materiales calcolíticos y del Bronce Antiguo y Medio, propició una aproximación a los contextos socio-culturales en los que se desarrolló la metalurgia temprana de la península, recogida en un volumen coordinado por Delibes y Montero Ruiz (1999). Más tarde se publicaron las metalografías obtenidas
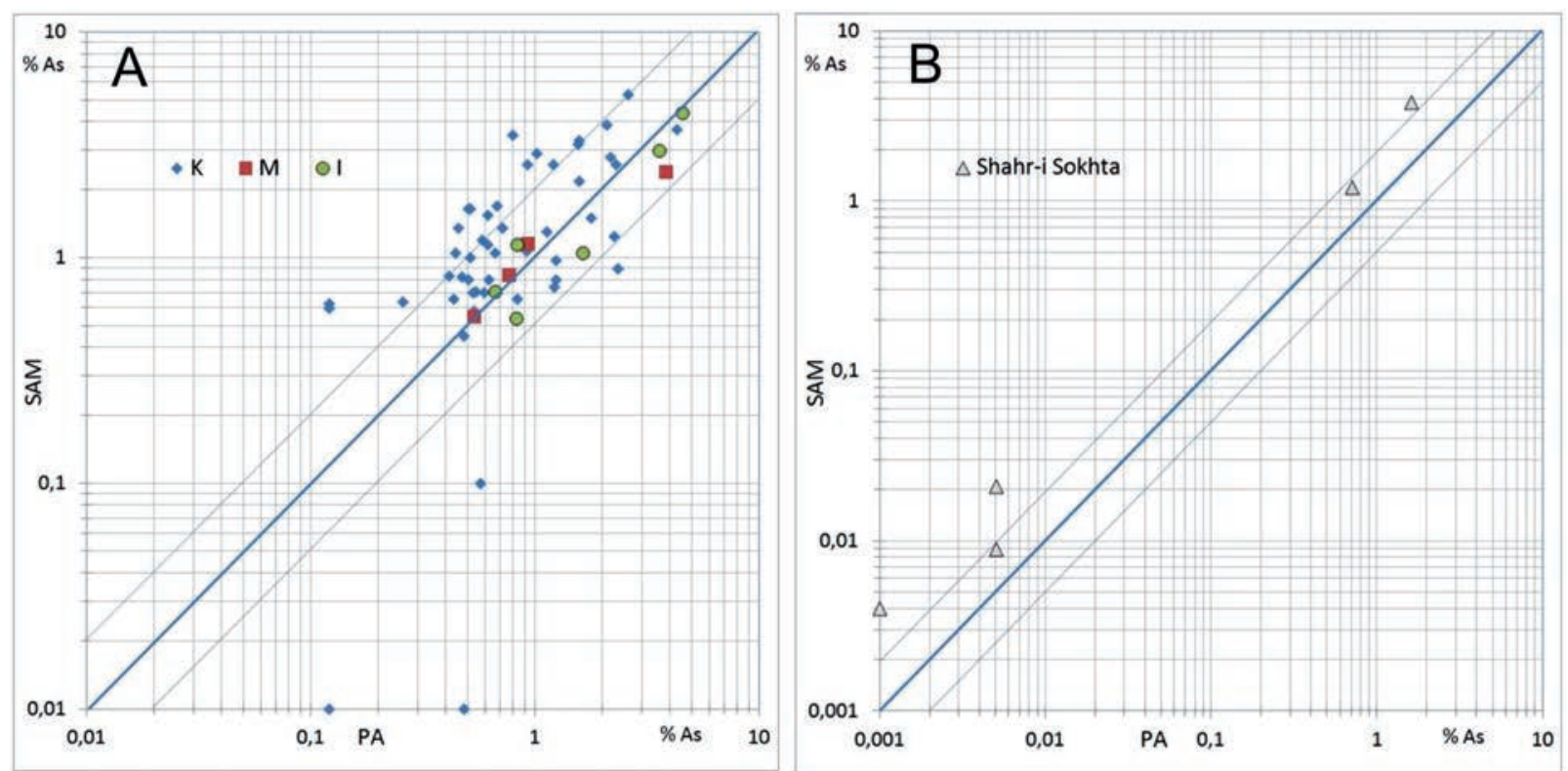

Fig. 9. Comparación de los contenidos de arsénico en análisis de un mismo objeto: A. análisis realizados por el SAM y el PA con diferentes espectrómetros; B. análisis efectuados por Hauptmann et al. (2003: tab. 4) en varios puntos de masas metálicas del yacimiento de Shar-i-Shokhta, Iran (III milenio cal AC) (en color en la edición electrónica).

\begin{tabular}{|c|c|c|c|c|c|c|c|c|c|c|}
\hline $\mathbf{N}^{\mathbf{0}}$ Análisis & Fe & Ni & $\mathbf{C u}$ & $\mathbf{Z n}$ & $\mathbf{A s}$ & $\mathbf{A g}$ & $\mathbf{S n}$ & $\mathbf{S b}$ & $\mathbf{P b}$ & $\mathbf{B i}$ \\
\hline PA12530 & 0,04 & nd & 98,9 & nd & 0,92 & 0,025 & 0,01 & nd & nd & nd \\
\hline PA22273 & nd & nd & 98,9 & nd & 1,02 & nd & nd & nd & 0,06 & nd \\
\hline PA7603 & 0,08 & 0,07 & 99,4 & nd & $\begin{array}{c}0,39 \\
(0,99)\end{array}$ & 0,006 & tr & 0,005 & nd & - \\
\hline SAM 18166 & 0 & 0 & & 0 & 1,15 & 0 & 0 & 0 & 0 & \\
\hline
\end{tabular}

Tab. 6. Análisis elemental del hacha plana de la Cova M de Arbolí ( $\mathrm{n}^{\mathrm{o}}$ inv. 5008 Museo de Reus) realizado con distintos espectrómetros. El valor de arsénico entre paréntesis correspondería a la corrección necesaria para los análisis realizados con el Kevex explicada en el texto. 
hasta entonces y su interpretación, aventurando hipótesis sobre la evolución de la tecnología del metal desde el Calcolítico al Bronce Final (Rovira y Gómez Ramos 2003). A lo largo de los años se han ido añadiendo pinceladas al cuadro general de la tecnología metalúrgica prehistórica, utilizando los análisis más por su valor descriptivo (tipos de metal, técnicas de fabricación, etc.) que por el valor intrínseco de las cifras. En ese cuadro destacan algunos escenarios por su especial relevancia, a unos pocos de los cuales dedicaremos los apartados siguientes.

\subsection{Vasijas de reducción y escorias calcolíticas}

En la década de 1980 e incluso más tarde, la idea más comúnmente aceptada para explicar la obtención de cobre pasaba necesariamente por el uso de hornos metalúrgicos. Era una consecuencia lógica de retrotraer hasta los orígenes la manera actual de conseguir metal: los minerales son tratados en un horno (entendido como una cavidad cerrada de atmósfera controlada) en cuyo interior tiene lugar la transformación del mineral en metal. Sin embargo, cuando a comienzos de dicha década comenzamos a estudiar los desechos metalúrgicos calcolíticos de Almizaraque (Almería) y su contexto, sorprendía la escasez de escorias y la relativa abundancia de fragmentos de vasijas cerámicas con un gruesa capa escorificada en su cara interna (Fig. 10). Tampoco se había encontrado en el sitio ninguna estructura claramente asignable a restos de un horno y las evidencias arqueometalúrgicas parecían distribuirse homogéneamente en los ambientes domésticos.

Los primeros análisis por $X R F$ ya sugerían composiciones complejas para estas escorificaciones que parecían obedecer a reacciones químicas ocurridas entre la carga mineral y la cerámica, a alta temperatura. Persuadidos de la necesidad apriorística de que hubiera hornos, en una primera publicación aparecida en 1989 como consecuencia de un congreso internacional celebrado en Madrid en 1985, propusimos que

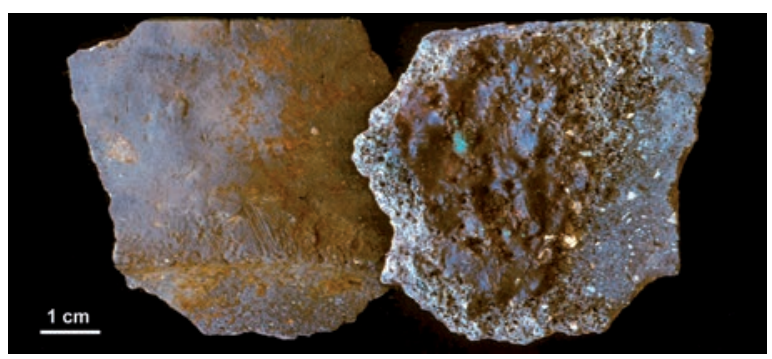

Fig. 10. Fragmento de vasija de reducción de Almizaraque (Almería). Obsérvese la potente escorificación de la cara interna de la cerámica (en color en la edición electrónica). debía tratarse de fragmentos de grandes vasijas que sirvieron de cámara de reducción que se colocarían en el interior del horno (Delibes et al. 1989: 88) según un esquema en la línea de una propuesta recogida por Tylecote (1979: 17, fig. 6) para la fundición de metal amortizado.

Poco después cambiamos de hipótesis prescindiendo de la idea de horno: las vasijas eran en sí el "horno" (Delibes et al. 1991: 307), usando a partir de entonces y durante algún tiempo la expresión "vasijas-horno" para describir la manera de obtener cobre de sus minerales en época calcolítica. Para entonces ya se había publicado el artículo donde Zwicker et al. (1985) documentaban el uso de este método durante una amplia horquilla cronológica.

El modelo se fue perfeccionando con nuevos estudios dentro del PA y con las aportaciones de otros colegas, de manera que cada vez era más frecuente encontrar trabajos en los que se hablaba de vasijas empleadas para la reducción de minerales (smelting crucibles) (p. ej. Craddock 1995: 133; Hauptmann et al. 1996: 4). La idea comúnmente aceptada en la actualidad es que la metalurgia primera comenzó en el Neolítico avanzado en aquellos lugares donde se han encontrado evidencias del uso de vasijas de reducción (Hauptmann 2007: 217-219; Dolfini 2013: 27, 2014: 495) o de simples cubetas excavadas en el suelo (Dolfini 2014: 485, fig. 18.6; Radivojević y Rehren 2015: 230) cuyo principio de funcionamiento es el mismo.

Sorprendentemente, mientras en otras regiones los metalúrgicos desarrollaron o adoptaron la estructura del verdadero horno a finales del Calcolítico local, en la Península Ibérica seguiremos encontrando fragmentos de cerámica escorificada hasta la Edad del Hierro. El cambio tecnológico que supone el uso de hornos lleva aparejada la aparición de un nuevo tipo de escoria mejor estructurada que la anterior debido a que a la carga se añaden sistemáticamente fundentes para lograr un material de bajo punto de fusión que mejora, entre otras cualidades, la separación del metal.

Las estructuras de fuego sencillas, abiertas, como son las usadas para reducir mineral en una vasija o en una cubeta, producen una escoria de composición muy variable, que retiene mucho metal (Bourgarit 2007: 6, fig. 3). Es debido a su elevada viscosidad, que a su vez se relaciona con la composición de la ganga que acompaña al mineral y a la dificultad para mantener estable la temperatura y la atmósfera del reactor donde tienen lugar las reacciones químicas de transformación. La escoria asociada a la vasija de reducción se caracteriza por su heterogeneidad intrínseca y por su variabilidad de unos yacimientos a otros, pero todas tienen en común ciertos rasgos, como son la presencia de relictos del mineral original, espinelas (habitualmente magnetita) y la frecuente formación de delafosita en una matriz

Trab. Prehist., 75, N. ${ }^{\circ}$ 2, julio-diciembre 2018, pp. 223-247, ISSN: 0082-5638

https://doi.org/10.3989/tp.2018.12213 
piroxénica en la que precipitan al enfriar cristales de hedenbergita, anortita, melilita y otros silicatos (Rovira y Montero Ruiz 2013: 232-234). En cambio las de horno son estructuralmente más sencillas y están constituidas generalmente por olivino (fayalita) en una matriz escasa de vidrio de relleno. Esta clara diferencia puede servir para distinguir la escoria inmadura de vasija de reducción de la de horno, aun suponiendo que no quedara rastro de este último en el registro arqueológico. Pero de momento no se ha encontrado ningún ejemplar de ésta última en los yacimientos prehistóricos con metalurgia del cobre de la Península Ibérica.

\subsection{El cobre arsenical, un tema a debate}

Desde que Charles (1980) esbozara su modelo evolutivo de las aleaciones, se viene considerando que el cobre arsenical fue un hallazgo importante de los primeros metalúrgicos con el que conseguían superar las propiedades mecánicas del cobre más o menos puro. Esta afirmación debe ser matizada inmediatamente porque, si por mejora entendemos una mayor dureza del cobre arsenical, ésta no se hace claramente perceptible mientras no se alcancen concentraciones en torno al $3 \%$ As en la liga. Así lo deducimos de los estudios experimentales realizados por Lechtman (1996) en los que el valor de la dureza de una probeta deformada en frío hasta reducir su espesor a la mitad va pasando de $125 \mathrm{HV}$ para cobre con $0 \%$ As; a $134 \mathrm{HV}$ con $1 \%$ As; a $150 \mathrm{HV}$ con $2 \%$ As; $170 \mathrm{HV}$ para $3 \%$ As, etc. Es, pues, a partir del 2-3\% As cuando el incremento de dureza puede tener algún significado en términos de funcionalidad del cobre prehistórico. Sobre esta cuestión volveremos más adelante.

Si los cobres arsenicales fueron aleaciones intencionadas o fortuitas es un viejo debate al que nosotros nos incorporamos en 1989 inclinándonos por la idea, basada en los análisis de los materiales de Almizaraque, de que su obtención era fortuita (Delibes et al. 1989: 89). En la década de 1930, W. Witter justificaba su opinión en contra de la intencionalidad por la reducción de minerales polimetálicos. En el mismo sentido se expresaba Pazukhin en 1964 (véase, para no alargarnos en exceso en esta cuestión, la revisión de opiniones que hizo Selimkhanov 1982). En nuestro caso eran los minerales, escorias y objetos metálicos de Almizaraque los que apoyaban esa opción de no intencionalidad.

Buscando una posición conciliadora, Tylecote (1991: 221) proponía que aleaciones de hasta el $2 \%$ As podían deberse a la reducción de minerales cobre-arsénico, pero que porcentajes superiores se obtendrían por coreducción de minerales de cobre y de arsénico o por cementación de cobre con minerales de arsénico.

Estando así las cosas, en 1997 presentamos en un coloquio internacional un estudio sobre la metalurgia campaniforme (Rovira 1998). Al representar en un histograma las concentraciones de arsénico de los metales de ese horizonte obtuvimos un gráfico de barras cuya función característica es una curva lognormal que claramente aludía a un proceso natural donde no se apreciaba voluntad alguna de seleccionar una franja determinada de composiciones, como debería suceder si los metalúrgicos hubieran deseado obtener metales con más de $3 \%$ As (Rovira 1998: 110, fig. 2), tal como sucedería luego con las aleaciones cobre-estaño, que tienden a conformar curvas gaussianas. A la misma conclusión había llegado antes Pernicka (1990), citado por Müller et al. (2007: 17), para quien la distribución lognormal indicaba que el arsénico provenía de los minerales procesados y no podía controlarse directamente por el fundidor. En la actualidad, con un número de análisis mucho mayor, la distribución es la correspondiente a la figura 11 cuya función sigue dibujando una curva lognormal. Como puede apreciarse, la mayoría de las aleaciones tienen menos del $3 \%$ As, lo cual parece contradecir la presumida voluntariedad por conseguir sistemáticamente aleaciones mejoradas. Los metales portugueses muestran una distribución similar (Müller et al. 2007: 19, fig. 5) y lo mismo sucede con los franceses estudiados por Labaune (2013: 184-186 y fig. 9).

Esto no significa que los metalúrgicos prehistóricos no apreciaran a posteriori diferencias entre el cobre con y sin arsénico. La más evidente es el color, que va cambiando de los tonos cobrizos a los amarillentos conforme aumenta el contenido de arsénico, y esta propiedad no pudo pasar desapercibida. Cuestión aparte es si dicha propiedad fue utilizada para elaborar determinados tipos de objetos, un tema sobre el que existe abundante literatura intentando justificar, por poner un caso, mayores porcentajes de arsénico en los puñales que en las hachas. En nuestra opinión sí hubo selección pero mucho más aleatoria de lo que se pretende, como veremos.

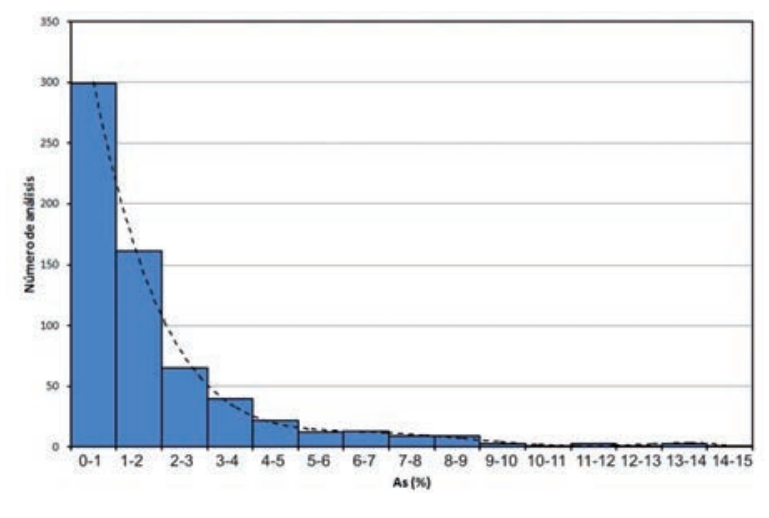

Fig. 11. Histograma correspondiente a las aleaciones cobre-arsénico calcolíticas de la Península Ibérica. Las concentraciones con más del $10 \%$ As hay que tomarlas con reservas pues corresponden a metales fuertemente corroídos. Valores recalculados según Innov-X. 
Considerando los contenidos de arsénico de los puñales, las hachas, las puntas de flecha, los punzones y los cinceles analizados en el PA, los ejemplares con más del $3 \%$ As constituyen grupos minoritarios en todos estos tipos (Fig. 12). La relación más favorable entre los menos y los más arsenicados es de 2,4/1 para los puñales, seguida de $3,4 / 1$ para los punzones, 5/1 para cinceles, $6,1 / 1$ para puntas de flecha y $6,3 / 1$ para las hachas. Podría interpretarse que hay una mayor selección del metal a la hora de elaborar un puñal que un hacha. Pero esta parece una explicación en exceso simplista porque si consideramos los valores medios del arsénico y su desviación típica $(1,65 \pm 7,14$ en las hachas y 2,60 \pm 4,72 en los puñales) resulta que hay valores máximos de arsénico prácticamente coincidentes en ambos tipos. Es decir los dos conjuntos tienen ejemplares con mucho arsénico, lo cual ya sugiere cierta aleatoriedad no estrictamente tecnológico-funcional en la selección del metal, que invalida en cierto modo la propuesta del uso de recetas concretas aplicadas según el tipo de objeto a producir.

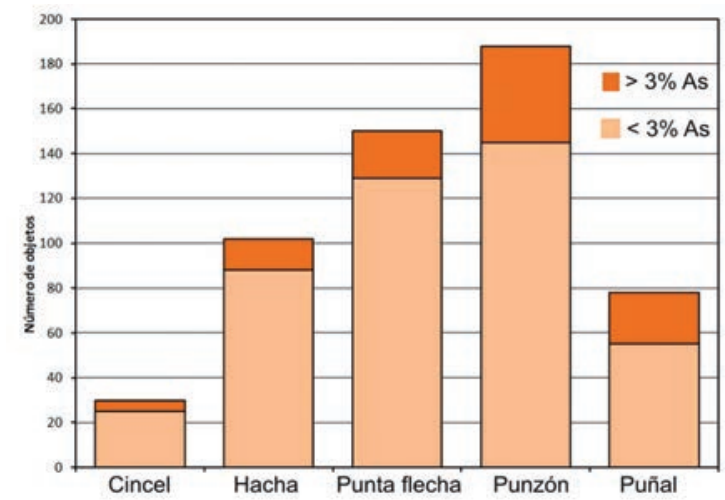

Fig. 12. Histograma representando el número de objetos de varios tipos según su contenido de arsénico, considerando la cifra de corte el $3 \%$ As.

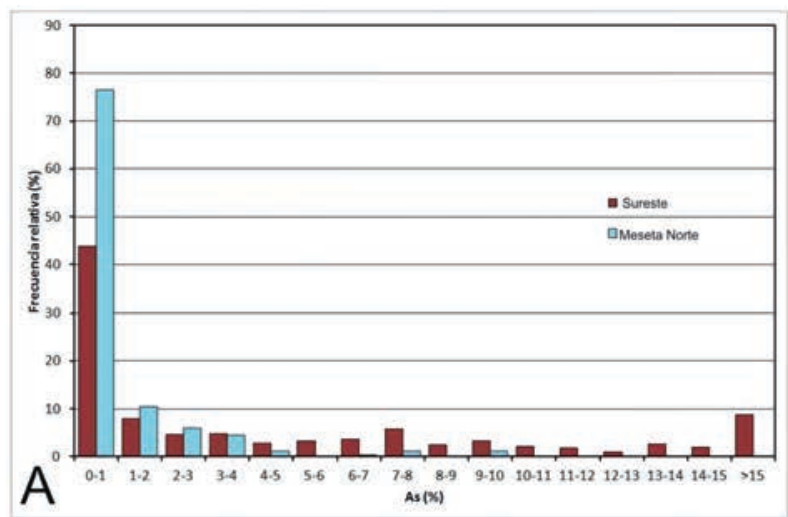

Cualquier intento de explicar esas diferencias reales no deja de ser una lícita elucubración y nosotros sugerimos en otro lugar una explicación basada en los conceptos de metal circulante y metal amortizado (Rovira y Delibes 2005: 499-500), que a su vez está relacionada con los contextos de los hallazgos. Las hachas, consideradas herramientas, se encuentran predominantemente en ambientes de poblados y forman parte del metal circulante que se nutre constantemente de metal nuevo y de metal reciclado. Los puñales, en cambio, en su mayoría proceden de sepulturas; es decir es metal que se amortiza apartándolo de la circulación. Tanto si un puñal fue elaborado con metal nuevo o fue producto del reciclado, es lógico pensar que tras formar parte del ajuar de una tumba no volviera a entrar en el circuito de reciclaje. Como es sabido, al reciclar cobre arsenical se producen importantes pérdidas de arsénico debidas a su volatilidad (McKerrell y Tylecote 1972), por lo cual es de esperar que la tasa media de arsénico sea menor en el metal circulante, en su conjunto, que en el amortizado. Esta podría ser una explicación para la diferencia de medias de arsénico.

Sin embargo este argumento no es el más poderoso, en nuestra opinión, para rechazar la hipótesis de voluntariedad en la producción de cobre con arsénico. Si nuestra hipótesis es cierta, la mineralogía es determinante. El PA ha analizado varios cientos de muestras de mineral, unas procedentes de yacimientos arqueológicos y otras de las muchas minas de cobre prospectadas. En la figura $13 \mathrm{~A}$ se representa la distribución de las concentraciones de arsénico medidas en dichos minerales según procedan de la Meseta Norte o del Sureste de la península. Hay una notable diferencia entre ambos conjuntos, resultando que los del Sureste tienen mucho más arsénico. Consecuentemente, habrá también diferencias entre los metales calcolíticos de ambas regiones, como así sucede en realidad (Fig. 13B).

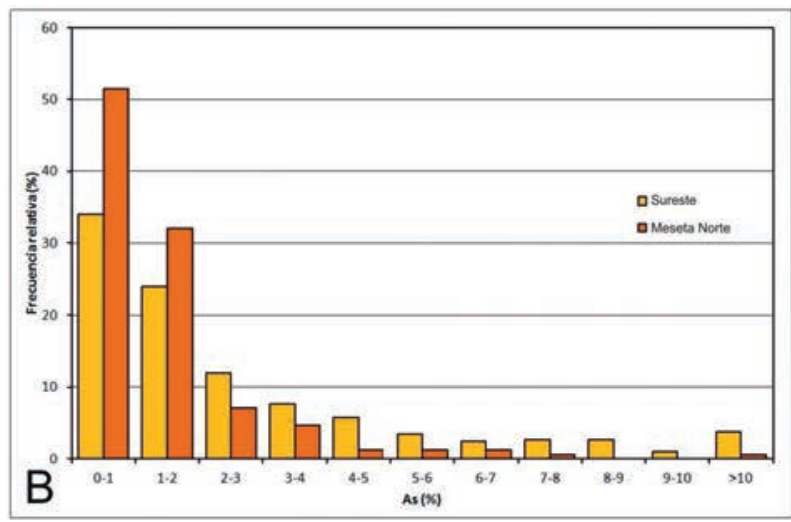

Fig. 13. Comparación del contenido de arsénico en minerales (A) y objetos calcolíticos (B) de la Meseta Norte y del Sureste peninsular (en color en la edición electrónica).

Trab. Prehist., 75, N. ${ }^{\circ}$ 2, julio-diciembre 2018, pp. 223-247, ISSN: 0082-5638

https://doi.org/10.3989/tp.2018.12213 
Habría todavía otro argumento en favor de nuestra hipótesis: los intentos de correlacionar composición, dureza del metal y proceso de fabricación del objeto conducen a un callejón sin salida al concluir que no hay evidencia suficiente de que el metalúrgico prehistórico supiera o pudiera aprovechar las ventajas teóricas del cobre arsenical para optimizar sus fabricados. Así lo sugieren los trabajos de Rodríguez Bayona et al. (2010: 213, tab. 3) y Pereira et al. (2012: 169, fig. 7). Ya anteriormente Budd (1992) había demostrado la existencia de fases antagónicas en las cadenas operativas usadas para fabricar los objetos, que afectaban al contenido final de arsénico.

Ante esta situación, el color cobra probablemente mayor protagonismo que las propiedades mecánicas del objeto, seleccionando el cobre más arsenical (más amarillento) según criterios finalistas (p. ej. prestigio del propietario) con poca relación aparente con la tecnología. No son pocos los autores que ya toman en consideración esta opción. Recientes estudios como el de Mödlinger et al. (2017) o el de Radivojević et al. (2018) profundizan en los aspectos colorimétricos de gran variedad de aleaciones, incluidas las que contienen arsénico, e insisten en la importancia del color de las aleaciones prehistóricas, preguntándose hasta qué punto esa cualidad estética pudo primar a la hora de escoger un material para fabricar un objeto sobre otras propiedades relacionadas con cuestiones mecánicas (Mödlinger et al. 2017: 22), dándole una mayor dimensión social a la tecnología.

El debate no está cerrado y hace poco Escanilla et al. (2016) concluyen tras un documentado estudio de minerales, escorias y otros subproductos metalúrgicos del yacimiento calcolítico de Agua Amarga (Murcia), que los metalúrgicos co-reducían minerales locales cupro-ferruginoso y minerales arseno-cuprosos traídos de la vecina Cuenca de Vera con la finalidad de obtener cobre arsenical. Esta forma de proceder del metalúrgico no se opone frontalmente a nuestra hipótesis, pues es razonable pensar que empíricamente se puede llegar a la conclusión de que ciertas mineralizaciones producen un metal más amarillo. Nuestra idea de la no intencionalidad se refiere básicamente a la falta de control del contenido de arsénico en el metal resultante y en los objetos con él producidos, no sólo a la interpretación de las fases minerales y metálicas de las escorias. El número de objetos calcolíticos analizados procedentes del área en estudio por estos investigadores (el Valle del Guadalentín) es pequeño (14 piezas) y los tenores de arsénico se mueven entre $0,33 \%$ y $4,14 \%$ As, con una media de 0,86 \% As (Escanilla 2016: 378, tab. 7.1), cifras poco representativas para hablar de buenos cobres arsenicales pues de ellos sólo dos superan el $3 \%$ As. Los cuatro objetos murcianos analizados por el PA, de Totana, Bullas y Jumilla, caen dentro de ese intervalo de composiciones.

\subsection{Escala y organización de la producción}

Una perspectiva diacrónica y de amplitud geográfica suficiente como la que ofrece la Península Ibérica permite observar cambios en el tiempo y en el espacio. La identificación en el registro arqueológico de un número mayor o menor de metales y restos metalúrgicos puede ser circunstancial, sin embargo el nivel tecnológico que se define a partir de los restos es independiente de su mayor o menor abundancia. Y son precisamente esos rasgos tecnológicos una de las bases para argumentar la capacidad y la escala productiva de un determinado grupo cultural. Las diferencias de interpretación en estas cuestiones tecnológicas tienen implicaciones directas sobre las valoraciones económicas, sociales y políticas propuestas sobre el papel de la metalurgia.

En la década de los 1980 se consideraba a El Argar una cultura de metalúrgicos altamente especializada, explicando su desaparición por el agotamiento de los recursos minerales y por el impacto de esta tecnología en el medio (deforestación por necesidades de combustible) (Lull 1983). También en el Suroeste investigadores como Nocete (2004) han propugnado escalas productivas elevadas con capacidad de impacto ecológico. En ambos supuestos la premisa de la especialización y de la alta capacidad productiva se basa en una percepción actualista de esta actividad y en una valoración del registro arqueometalúrgico poco crítica (véase Rovira 2016 sobre la situación en el Suroeste).

Por el contrario, desde el PA se ha defendido para ambas zonas, así como para el resto de la Península Ibérica, la hipótesis de una escala doméstica de producción a partir de una tecnología primitiva cuya capacidad productiva estaba condicionada, como ya se ha comentado, por su bajo rendimiento y por estructuras con volumen reducido de producción. Dados los pocos cambios tecnológicos denotados por las escorias y las vasijas de reducción desde el Calcolítico al Bronce Medio (Rovira et al. 2015: 361-362), se ha argumentado que la única forma de incrementar la producción de metal era repitiendo o multiplicando las unidades de trabajo (Rovira 2016: 64), cuyo número máximo está limitado por la población y el espacio ocupado en los asentamientos.

Esto no quiere decir que no se observe un incremento relativo entre el metal consumido en el Calcolítico y la Edad del Bronce, con un metal que va aumentando su valor social. Pero la escala de la producción no tuvo capacidad suficiente para generar situaciones críticas de colapso de recursos. La abundancia de minerales de cobre, su amplia distribución por toda la superficie peninsular y su accesibilidad y fácil identificación en superficie puso al alcance suficientes recursos que hicieron que el cobre no fuera un elemento estratégico controlable y que su distribución y consumo tuviera un carácter preferentemente regional. 
Los isotopos de plomo empiezan a definir mejor este consumo regionalizado $\mathrm{y}$, a la vez, diversificado de cobre. En este esquema productivo de escala limitada se entiende la habitual presencia de minerales (Tab. 4) en asentamientos distantes de las minas. Las áreas especializadas de reducción del mineral cerca o a pie de mina son características de las explotaciones intensivas y en consecuencia de una mayor producción de metal. En cambio, en la fase inicial, doméstica, el mineral se desplazaba hasta los poblados, como se ha comprobado en las importantes zonas mineras de Timna (Israel) y Faynan (Jordania). Además este fenómeno llevó aparejada la invención del verdadero horno metalúrgico de mucha mayor capacidad productiva (Hauptmann 2007).

Desde mediados del II milenio cal AC se empiezan a detectar cambios significativos en la producción metalúrgica, no sólo por la generalización de la aleación del cobre con el estaño (bronce) cuya expansión nortesur, ya propuesta hace años (Fernández-Miranda et al. 1995), ha sido corroborada también a nivel europeo (Pare 2000), sino por una cierta homogeneización en la composición del metal, interpretable como un cambio en los recursos minerales utilizados, en los que la sustitución de menas arsenicales da paso al aprovechamiento preferente de minerales de mayor pureza. Durante el Bronce Final predomina un metal con un nivel muy bajo de impurezas y los contenidos de estaño tienden a ser elevados (valores medios por encima del $10 \% \mathrm{Sn}$ ). La incorporación a redes comerciales más amplias como las del mundo atlántico, y en su fase final con el comercio colonial fenicio del Mediterráneo oriental, tiene su reflejo en la escala de la producción. Un síntoma de ese cambio vinculado a una mayor producción y circulación del metal son los lingotes de cobre, y aunque de nuevo los isotopos de plomo siguen reflejando una amplia variedad de recursos explotados especialmente en el sur peninsular, se perfilan áreas con una mayor intensificación como el distrito minero de Linares (Jaén) (Montero et al. 2012).

Otro de los temas investigados por el PA se relaciona con los cambios tecnológicos que el contacto regular con el Mediterráneo oriental produjo durante la primera mitad del I milenio $\mathrm{AC}$, que propician y permiten un cambio en la escala productiva. Como ya apuntó Hunt-Ortiz (2003) en su tesis doctoral, tanto la nueva producción de hierro, como la explotación de la plata a través de la técnica de copelación son deudoras de esos contactos. Pero también se producen cambios en la tecnología de horno para la reducción del cobre (Renzi 2013) y sobre todo se identifican los rasgos de una organización planificada por los intereses comerciales fenicios, que controlan la distribución de los productos metálicos y consiguen orientar la economía de las poblaciones indígenas para que cubran su demanda
(Murillo-Barroso et al. 2016) con un claro incremento en la escala de producción respecto a periodos previos.

Estos cambios de escala productiva propuestos a través de los cambios en la tecnología metalúrgica están siendo confirmados por los estudios de contaminación ambiental, cada vez más frecuentes (Leblanc et al. 2000; García Alix et al. 2013; Martínez Cortizas et al. 2016; Manteca et al. 2017). Vistos en su conjunto muestran, con las debidas variaciones regionales vinculadas a la mayor o menor intensidad de las explotaciones mineras y del metal extraído $(\mathrm{Pb}$ o $\mathrm{Cu})$, que en el Calcolítico (hacia el 4500 cal BP) se detectan los primeros indicios de actividad metalúrgica, pero siempre a un nivel reducido. También se identifica, tras unos mínimos hacia el 3500 cal BP, una tendencia ascendente de la contaminación que se incrementa hacia el 2700 cal BP llegando a su apogeo durante época romana republicana y se mantiene hasta el siglo III de la Era, produciéndose a continuación un brusco declive de la contaminación por metales.

\subsection{La metalurgia del hierro}

El tema de la arqueometalurgia del hierro en la Península Ibérica sobre el que el PA ha venido trabajando en los últimos años tiene enormes lagunas que es de esperar se vayan rellenando conforme aumente el registro arqueológico. Por el momento la producción de hierro es una gran incógnita al seguir faltando la escoria, un subproducto esencial. O quizás sea más apropiado decir que falta (o no tenemos) un buen criterio para reconocer lo que pudieran ser las escorias más primitivas de la producción de hierro. La situación es muy similar probablemente a la que teníamos hace una veintena de años con las escorias y los hornos más antiguos de la metalurgia del cobre. Esta situación ya la planteábamos en el congreso internacional The World of Iron celebrado en Londres en 2009 (Renzi et al. 2013) donde se revisaban los hallazgos anteriores y presentábamos nuevos análisis del yacimiento fenicio antiguo de La Fonteta en Guardamar de Segura (Alicante) y su interpretación, que luego serían re-evaluados por Martina Renzi (2013) en su tesis.

El panorama es muy similar en todas partes, incluso en los territorios de donde procedían los fenicios en las regiones costeras del Mediterráneo Oriental. La tecnología de obtención de hierro a comienzos de la Primera Edad del Hierro es una incógnita. Sobre el asunto volvíamos a insistir en aquellos años (Renzi y Rovira 2015), incidiendo en las dificultades de identificar las escorias y proponiendo como hipótesis de trabajo que esa "invisibilidad" de la primera siderurgia podía deberse al aprovechamiento de minerales de hierro muy puros, procesados en hornos muy sencillos, sin apenas

Trab. Prehist., 75, N. ${ }^{\circ}$ 2, julio-diciembre 2018, pp. 223-247, ISSN: 0082-5638

https://doi.org/10.3989/tp.2018.12213 
producción de escoria. Aunque desde aquí seguimos trabajando en esa dirección, somos conscientes de que el problema es mucho más general y atañe a varios países. Un proyecto mancomunado podría acelerar la solución.

\subsection{La Arqueometalurgia como debate}

Conforme el PA fue cumpliendo años y se fueron publicando resultados, fue creciendo el interés entre los arqueólogos y las instituciones por la Arqueometalurgia. A finales de la década de 1980, y sobre todo en la siguiente, se abrieron nuevas líneas de trabajo e investigación en los laboratorios de muchas Facultades de Ciencias que hasta entonces destinaban sus equipos primordialmente a las ciencias puras. El PA no fue ajeno a que se produjera esa apertura pues, como se recordará, nuestros objetivos encaminados hacia un concepto más complejo y comprehensivo de la metalurgia pretérita necesitaban imperiosamente aprovechar los recursos logísticos de esos laboratorios a través de proyectos conjuntos o financiados.

Desde mediados de la década de 1990 publicaciones gestadas fuera del PA fueron animando un foro de discusión (al menos en lo que se refiere al uso de bibliografía) en un amplio espectro de la problemática. Esta, a su vez, se reflejaba en congresos y reuniones periódicas dentro de la península (destacamos aquí el gran papel jugado por congresos como los Ibéricos de Arqueometría, que ya van por la XII edición) y, lo que es más alentador, la creciente representación española en eventos internacionales periódicos sólidamente establecidos, como el Symposium International on Archaeometry y la Archaeometallurgy in Europe International Conference, y en otros ocasionales. Desde el inicio, los miembros del PA veíamos imprescindible participar en los foros internacionales desde una doble vertiente: allí nuestro trabajo podía ser evaluado con rigor y era donde se presentaban las tendencias metodológicas más actualizadas que nos han servido y sirven para enriquecer nuestro quehacer. Gracias a esos repetidos contactos hemos establecido inmejorables relaciones con colegas que superan en muchos casos lo estrictamente profesional, o hemos tenido el honor de formar parte en numerosas ocasiones de comités científicos internacionales.

El desarrollo del PA no pasó inadvertido en los departamentos correspondientes de algunas Facultades de Geografía e Historia. Participamos en seminarios y cursos más o menos especializados, bien para hablar de metodología, bien para presentar resultados y cómo éstos iban configurando nuevas ideas sobre la evolución de la metalurgia prehistórica y su impacto social. La Arqueometalurgia sigue sin formar parte de las asignaturas curriculares de nuestras Facultades; sin embargo, el interés por ella queda reflejado en la inclusión de materias afines en muchos de los másteres que se imparten sobre Patrimonio, en algunos de los cuales participamos.

Finalmente, en los últimos años se han consolidado en Portugal grupos de investigación arqueometalúrgica muy activos, como los del Centro de Ciências e Tecnologias Nucleares, el Instituto Superior Técnico de la Universidad de Lisboa o el Laboratorio Hércules de la Universidad de Evora, cuyos trabajos completan y añaden información valiosa al debate sobre la Arqueometalurgia peninsular.

\section{DESARROLLO FUTURO}

La información obtenida en este periodo de 35 años es mucha y cubre toda la Península Ibérica, pero es evidente que hay desequilibrios en cuanto a la representatividad geográfica dependiendo de la cronología y que tanto el periodo romano como el medieval pueden considerarse poco representados. Sin embargo, al corresponder a un mundo más globalizado estos aspectos geográficos pierden relevancia respecto al de la Prehistoria, donde los desarrollos culturales tienen un carácter más regional y necesitan una mejor caracterización de cada una de las zonas geográficas a comparar.

En consecuencia una de las líneas de trabajo futuro será ir completando datos de las zonas y periodos menos conocidos y mantener la disponibilidad de los estudios metalúrgicos para los nuevos hallazgos arqueológicos, pero la principal preocupación será preparar el acceso abierto de la información.

Una de las palabras clave de referencia actualmente es Big data. Nuestras bases de datos estrictamente no constituyen un caso de Big data, pero sí son una información que puede ser incorporada para su estudio en diseños de Big data, añadiendo capas de información del registro arqueológico y en combinación con los sistemas de información geográfica e infraestructuras de datos espaciales.

Christine Borgmann (2015) en su libro sobre el manejo de la información en la investigación académica desarrollan tres ideas a las que remitirse para compartir nuestros datos en abierto:

Tener datos correctos es mejor que tener muchos datos: no se trata del volcado directo de toda la información tal y como actualmente está recogida. Los datos accesibles deberán ser sólo los que puedan ser útiles de manera comparativa y no generen ruido o confusión. En consecuencia algunos análisis cualitativos o que no se pudieron hacer en condiciones óptimas (por ejemplo sin limpieza de su superficie) deberán ser filtrados. Los datos de yacimientos multifásicos donde 
carecemos de una completa identificación de la fase a la que se adscribe cada pieza deberán esperar a que esa información contextual esté disponible.

Es difícil compartir datos, ya que los incentivos para hacerlo son mínimos y la información puede variar mucho entre disciplinas. Ya hemos comentado la dificultad de comparar análisis obtenidos con técnicas y laboratorios distintos, y hemos insistido en la compatibilidad general de los datos del PA con las grandes series de análisis europeas. Las propuestas del proyecto FLow of Ancient Metals across Eurasia (FLAME) para el aprovechamiento y manejo de los datos analíticos antiguos y su sistema de clasificación de grupos de cobre (Pollard et al. 2015) son un marco adecuado para integrar los datos de la Península Ibérica en el contexto europeo. La clasificación en grupos sin embargo, ajusta mejor si el valor límite del elemento se sitúa en el $0,15 \%$ en vez del $0,1 \%$ originalmente propuesto, como se aprecia en la comparativa de los análisis comunes entre el $S A M$ y PA (Fig. 14).

Los datos no tienen valor o significado aislados. El conjunto de análisis del PA tiene significado por sí mismo, pero su valor se incrementa si puede ser integrado en una perspectiva más amplia y sobre todo si puede ser manejado por un mayor número de investigadores. El acceso abierto a través de la plataforma IDEARq (http://idearqueologia.org/) (Fernández Freire et al. 2013), que constituye una infraestructura de datos espaciales, es el objetivo próximo. Permitirá el uso de los datos correctos por parte de la comunidad científica, al tiempo que relaciona el material de los yacimientos con su cronología a través de la base de datos de $\mathrm{C} 14$ ya disponible y ofrece las referencias bibliográficas para su mejor contextualización.

El manejo de un gran volumen de datos e información posibilita plantear problemas de investigación a una escala diferente de la hasta ahora manejada. Des- de el inicio el objetivo subyacente del PA era poder comprender en términos comparativos el papel de la metalurgia en el desarrollo de la complejidad social en la Península Ibérica. Gracias a estudios parciales ha sido posible publicar algunas síntesis o perspectivas generales sobre esa primera metalurgia. La información actual permite buscar explicaciones para fenómenos globales como los contactos culturales o la circulación de materias primas (en este caso el metal) en periodos posteriores y con una perspectiva geográfica más amplia. Los datos del PA sobre la Península Ibérica se complementan con las aportaciones de otros investigadores españoles y portugueses, así como con datos de composición de mayor precisión gracias al uso de otras técnicas de análisis, sin olvidar la necesidad de abordar casos de estudio, cuyos detalles permitan ir matizando o precisando las visiones generales.

Esa perspectiva globalizadora es precisamente la que nos hace reflexionar a menudo sobre la propia historia del PA, una historia que se inició con unos investigadores formados en el campo de las Humanidades que pretendían buscar respuestas nuevas que, en principio, sólo podían encontrarse en el campo de la Ciencia de los Materiales. Había que abrirse camino entre un sustrato de lugares comunes generados de modo poco crítico por las explicaciones que la investigación arqueológica había construido a mediados del siglo pasado. Necesitábamos una base analítica sobre la que cimentar nuevas hipótesis. Ese trabajo ya está en gran medida hecho y, desde esa perspectiva globalizadora, para avanzar hemos de aventurarnos por nuevos senderos. Ciertamente quedan sombras (muchas) que habremos de intentar aclarar desde una base analítica, pero la visión final ya no puede ser la metalurgia de tal o cual yacimiento sino cómo esa metalurgia se inserta en un paisaje social mucho más amplio. La Arqueometalurgia por sí sola no explica toda la complejidad
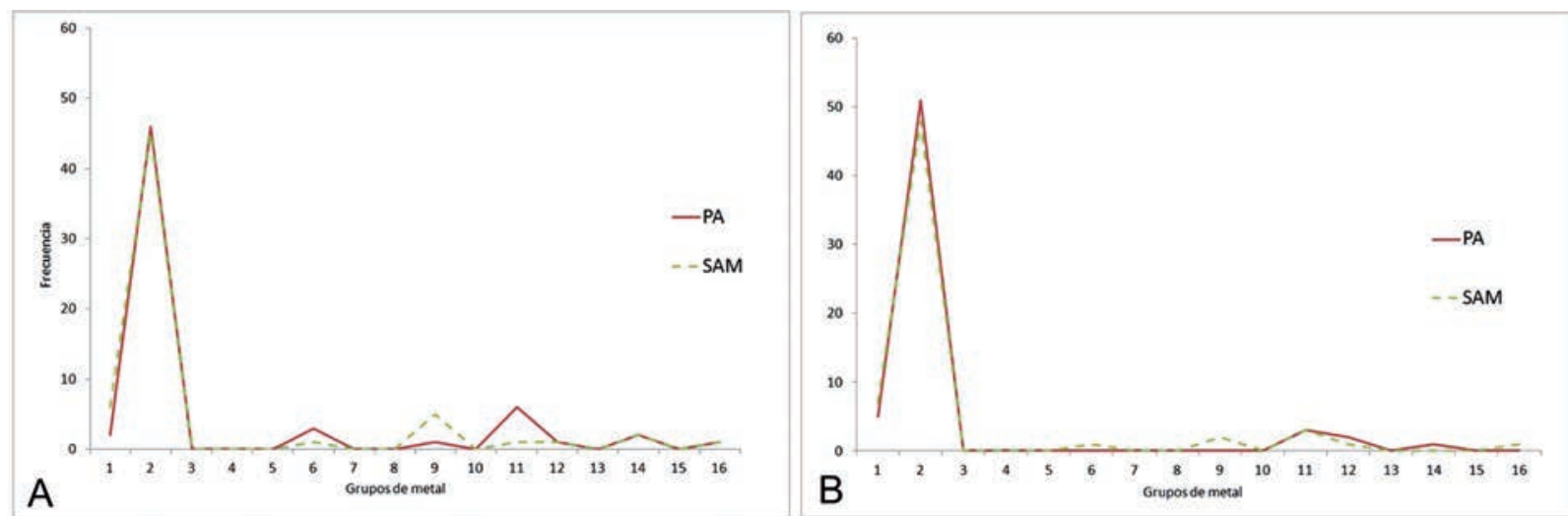

Fig. 14. Clasificación en grupos de metal de los objetos comunes analizados por el SAM y el PA: A. con el límite original propuesto por Pollard et al. (2015) del 0,1\% para la clasificación; B. con un límite de 0,15\% para la clasificación de los elementos.

Trab. Prehist., 75, N. ${ }^{\circ}$ 2, julio-diciembre 2018, pp. 223-247, ISSN: 0082-5638

https://doi.org/10.3989/tp.2018.12213 
de las sociedades pretéritas o, dicho de otro modo, sin conexiones disciplinares mucho más amplias no conseguiremos un retrato-robot satisfactorio de aquellas sociedades. El futuro del PA pasa necesariamente por actuar en conexión con esas otras disciplinas disolviéndose en ellas o con ellas para generar un corpus más sólido y multifacético.

\section{AGRADECIMIENTOS}

La relación de especialistas e instituciones con cuya colaboración se ha ido desarrollando el "Proyecto Arqueometalurgia de la Península Ibérica" sería tan extensa que imposibilita exponerla aquí en detalle. Hay otras personas con una vinculación especial al laboratorio en distintos momentos. Ya hemos mencionado a algunas como Susana Consuegra y Óscar García Vuelta. Otras como Mark Hunt, Marc Gener, Pablo Gómez Ramos, Carolina Gutiérrez-Neira, Martina Renzi, Mercedes Murillo Barroso y Pau Sureda fueron o siguen siendo colaboradores incondicionales. A todas ellas nuestro más sincero agradecimiento. Y ya más de cerca, agradecemos a Antonio Uriarte los mapas que ilustran este artículo.

\section{BIBLIOGRAFÍA}

Almagro Basch, M. 1958: "Un nuevo depósito de Bronce Final hallado en San Esteban del río Sil". Memorias de los Museos Arqueológicos 1954, 15: 21-26.

Almagro Basch, M. 1960: Inventaria Archaeologica. España. Fascículo 5. Instituto Español de Prehistoria. Madrid.

Ambert, P.; Balestro, F.; Laroche, M.; Figueroa, V. y Rovira, S. 2013: "Technological aspects of the earliest metallurgy in France: 'Furnaces' and slags from La Capitelle du Broum (Pèret, France)". En P. T. Craddock (ed.): The origins of metallurgy in Europe. Historical Metallurgy 47 (1): 60-74.

Ambert, P.; Figueroa, V.; Guendon, J.-L.; Klemm, V.; Laroche, M.; Rovira, S. y Strahm, Ch. 2009: "The copper mines of Cabrières Hérault in Southern France and the Chalcolithic metallurgy". En T. L. Kienlin y B. W. Roberts (eds.): Metals and societies. Studies in Honour of Barbara S. Ottaway. Universitätsforschungen zur Prähistorischen Archäologie, Band 169. Rudolf Habelt. Bonn: 285-295.

Asinelli, M. G. y Martinón-Torres, M. 2016: "Copper-alloy use in a Tirrhenian medieval town: the case of Leopoli-Cencelle (Italy)". Journal of Archaeological Science, Reports 7: 597-608. https://doi.org/10.1016/j.jasrep.2015.09.023

Blance, B. 1959: "Estudio espectrográfico de algunos objetos metálicos del Museo de Prehistoria de la Diputación de Valencia”. Archivo de Prehistoria Levantina VIII: 163-173.

Blance, B. 1974: Die Anfänge der Metallurgie auf der Iberischen Halbinsel. Studien zu den Anfängen der Metallurgie 4. Mann. Berlin.

Blanco Freijeiro, A. y Rothenberg, B. 1981: Exploración arqueometalúrgica de Huelva. Río Tinto Minera y Labor. Madrid.

Borgman. Ch. L. 2015: Big data, little data, no data: scholarship in the networked world. MIT Press. Cambridge (Mass.).

Bourgarit, D. 2007: "Chalcolithic copper smelting". En S. La Niece, D. Hook y P. Craddock (eds.): Metals and mines. Studies in Archaeometallurgy. Archetype. Londres: 3-14.

Budd, P. 1992: "Alloying and metalworking in the Copper Age of Central Europe". Bulletin of the Metals Museum (Japan) 17: 3-14.
Castaño, P; Delibes, G.; Fernández-Miranda, M.; Fernández-Posse, M. D.; Martín, C.; Montero Ruiz, I. y Rovira, S. 1991: "Application des méthodes archéométriques pour l'analyse du Chalcolitique du bassin de Vera, Almería, Espagne". Revue d'Archéométrie 15: 47-53. https://doi.org/10.3406/arsci.1991.1267

Chang, K. C. 1967: Rethinking Archaeology. Random House. New York.

Charles, J. A. 1980: "The coming of copper and copper-base alloys and iron: A metallurgical sequence". En T. A. Wertime y J. B. Muhly (eds.): The coming of the Age of Iron. Yale University Press. Newhaven: 151-181.

Chernykh, E. 1978: Gornoe delo i metallurgiya v drevneishei Bolgarii/ Mining and metallurgy in Ancient Bulgaria. Bulgarian Academy of Sciences Press. Sofia.

Clarke, D. L. 1968: Analytical Archaeology. Methuen. Londres.

Craddock, P. T. 1995: Early Metal Mining and Production. Edinburgh University Press. Edinburgh.

Delibes, G.; Fernández-Miranda, M.; Fernández-Posse, M. D. y Martín, C. 1986: "El poblado de Almizaraque, Almería". Homenaje a Luis Siret 1934-1984. Junta de Andalucía. Sevilla: 167-177.

Delibes, G.; Fernández-Miranda, M.; Fernández-Posse, M. D.; Martín Morales, C.; Montero Ruiz, I. y Rovira, S. 1991: "Almizaraque (Almeria, Spain). Archaeometallurgy during the Chalcolithic in the Southeast of the Iberian Peninsula”. En J.-P. Mohen y Ch. Éluère (eds.): Découverte du métal. Picard. París: 303-315.

Delibes, G.; Fernández-Miranda, M.; Fernández-Posse, M. D.; Martín Morales, C.; Rovira, S. y Sanz, M. 1989: "Almizaraque (Almería): minería y metalurgia calcolítica en el Sureste de la Península Ibérica". En C. Domergue (ed.): Minería y metalurgia en las antiguas civilizaciones mediterráneas y europeas, I Coloquio Internacional Asociado (Madrid 1985): 81-96. Madrid

Delibes, G. y Montero Ruiz, I. (eds.) 1999: Las primeras etapas metalúrgicas en la Península Ibérica. II. Estudios regionales. Instituto Universitario Ortega y Gasset y Ministerio de Educación y Cultura. Madrid.

Dolfini, A. 2013: "The emergence of metallurgy in the Central Mediterranean region: a new model". European Journal of Archaeology 16 (1): 21-62. https://doi.org/10.1179/1461957112y.0000000023

Dolfini, A. 2014: "Early metallurgy in the Central Mediterranean". En B. W. Roberts y Ch. P. Thorton (eds.): Archaeometallurgy in global perspective. Springer. Nueva York: 437-506.

Escanilla, N. 2016: Recursos minerales de cobre y su explotación prehistórica en el Sudeste peninsular. El Valle del Guadalentín. Tesis Doctoral. Universitat Autònoma de Barcelona. Barcelona. http://hdl.handle.net/10803/399293

Escanilla, N.; Bourgarit, D. y Mille, B. 2016: "Mezcla de minerales y cobre arsenical durante el Calcolítico. El excepcional caso de Agua Amarga (La Fuensanta, Lorca)". Alberca. Revista de la Asociación de Amigos del Museo Arqueológico de Lorca 14: 7-30.

Fernández-Freire, C.; Bosque-González, I. del; Vicent-García, J. M.; Pérez-Asensio, E.; Fraguas-Bravo, A.; Uriarte-González, A.;... y Parcero-Oubiña, C. 2013: "A cultural heritage application schema: Achieving interoperability of cultural heritage data in INSPIRE". International Journal of Spatial Data Infrastructures Research 8: 74-97.

Fernández-Miranda, M.; Montero, I. y Rovira, S. 1995: "Los primeros objetos de bronce en el occidente de Europa". Trabajos de Prehistoria 52 (1): 57-69. https://doi.org/10.3989/tp.1995.v52.i1.431

García-Alix, A.; Jiménez-Espejo, F. J.; Lozano, J. A.; Jiménez-Moreno, G.; Martínez-Ruiz, F.; García Sanjuán, L.;... y Scott Anderson, R. 2013: "Anthropogenic impact and lead pollution throughout the Holocene in Southern Iberia". Science of the Total Environment 449: 451-460. https://doi.org/10.1016/j.scitotenv.2013.01.081

Gutiérrez-Neira, P. C.; Gener, M.; González Marrero, M. C.; Montero Ruiz, I.; Onrubia Pintado, J. y Sáenz Sagasti, J. I. 2014: “Objetos metálicos de base cobre del yacimiento de Cueva Pintada (Gáldar, Gran Canaria)". Actas del X Congreso Ibérico de Arqueometría (Castellón 2013): 230-241. Castellón

Gutiérrez Neira, C.; Montero Ruiz, I. y Marcos Alonso, C. 2016: "Análisis elemental de las monedas de oro procedentes de la fragata Nuestra Señora de las Mercedes 1804". En P. Grañeda Miñón (ed.): Actas XV Congreso Nacional de Numismática (Madrid 2014): 643-654. Madrid

Hall, E. T. 1960: "X-ray fluorescence analysis applied to Archaeology". Archaeometry 3: 29-35. 
Hall, E. T.; Schweizer, F. y Toller, P. A. 1973: "X-ray fluorescence analysis of museum objects: a new instrument”. Archaeometry 15 (1): 53-78. https://doi.org/10.1111/j.1475-4754.1973.tb00076.x

Hartmann, A. 1970: Prahistorische Goldfunde aus Europa - Spektralanalytische Untersuchungen und deren Auswertung. Studien $\mathrm{zu}$ den Anfangen der Metallurgie 3, Mann. Berlin

Hartmann, A. 1982: Prähistorische Goldefunde aus Europa. II. Specktralanalytische Untersuchungen und deren Auswertung. Studien zu den Anfängen der Metallurgie 5, Mann. Berlin.

Hartmann, A. y Kalb, Ph. 1969: "Investigaciones espectro-analíticas sobre hallazgos hispánicos de oro". Archivo de Prehistoria Levantina XII: 93-98.

Hauptmann, A. 2007: The Archaeometallurgy of Copper. Springer. Berlin-Heidelberg.

Hauptmann, A.; Bachmann, H. G. y Maddin, R. 1996: "Chalcolithic copper smelting: new evidence from excavations at Feinan, Jordan". Archaeometry 1994, Ankara. The Proceedings of the $29^{\text {th }}$ International Symposium on Archaeometry (Ankara 1994): 3-10. Tübitak. Ankara

Hauptmann, A.; Rehren, Th. y Schmitt-Strecker, S. 2003: "Early Bronze Age copper metallurgy at Sharh-I Sokhta Iran, reconsidered". Der Anschnitt 16: 197-213.

Heginbotham, A.; Bezur, A.; Bouchard, M.; Davis, J. M.; Eremin, K.; Frantz, J. H.;... y Speakman, R. J. 2010: “An evaluation of interlaboratory reproducibility for Quantitative XRF of historic copper alloys". En P. Mardikian, C. Chemello, Ch. Watters y P. Hull (eds.) METAL 2010 International Conference on Metal Conservation. Clemson University. Clemson: 178-188.

Hunt-Ortiz, M. A. 2003. Prehistoric Mining and Metallurgy in SouthWest Iberian Peninsula. British Archaeological Reports International Series 1188. Archaeopress. Oxford.

Junghans, S.; Sangmeister, E. y Schröder, M. 1960: Metallanalysen Kupferzeitlicher und Frühbronzezeitlicher Bodenfunde aus Europas. Studien zu den Anfängen der Metallurgie 1, Mann. Berlin.

Junghans, S.; Sangmeister, E. y Schröder, M. 1968: Kupfer und Bronze in der Frühen Metallzeit Europas. Katalog der Analysen Nr. 985 10040. Studien zu den Anfängen der Metallurgie 2, 3. Mann. Berlin.

Junghans, S.; Sangmeister, E. y Schröder, M. 1974: Kupfer und Bronze in der Frühen Metallzeit Europas. Katalog der Analysen Nr. 10041 22000. Studien zu den Anfängen der Metallurgie 2, 3. Mann. Berlin.

Labaune, M. 2013: "Bell Beaker metallurgy in Western Europe". En M. P. Prieto Martínez y L. Salanova (eds.): Current researches on bell beakers. Proceedings of the $5^{\text {th }}$ International Bell Beaker Conference: from Atlantic to Ural (Poio, Pontevedra, Galicia, Spain 2011): 177-188. Santiago de Compostela

Leblanc, M.; Morales, J. A.; Borrego, J. y Elbaz-Poulichet, F. 2000: "4500 year old mining pollution in southwestern Spain: long-term implication for modern mining pollution”. Economic Geology 95: 655-662. https://doi.org/10.2113/gsecongeo.95.3.655

Lechtman, H. 1996: "Arsenic bronze: dirty copper or choosen alloy? A view from de Americas". Journal of Field Archaeology 23 (4): 477-514. https://doi.org/10.2307/530550

Lull, V. 1983: La Cultura de El Argar. Akal Editor. Madrid.

Manteca, J. I.; Ros-Sala, M. M.; Ramallo-Asensio, S.; Navarro-Hervás, F.; Rodríguez-Estrella, T.; Cerezo-Andreo, F.;... y Martínez-Andreu, M. 2017: "Early metal pollution in southwestern Europe: the former litoral lagoon of El Almarjal (Cartagena mining district, S.E. Spain). A sedimentary archive more than 8000 years old". Environmental Science and Pollution Research 24: 10584-10603. https://doi.org/10.1007/s11356-017-8682-5

Martínez Cortizas, A.; López-Merino, L.; Bindler, R.; Mighall, T. y Kylander, M. E. 2016: "Early atmospheric metal pollution provides evidence for Chalcolithic/Bronze Age mining and metallurgy in southwestern Europe". Science of the Total Environment 545-546: 398-406. https://doi.org/10.1016/j.scitotenv.2015.12.078

McKerrell, H. y Tylecote, R. F. 1972: "The working of copper-arsenic alloys in the Early Bronze Age and the effect on the determination of provenance". Proceeding of the Prehistoric Society 38 (1): 209-218. https://doi.org/10.1017/s0079497x00012111

Mödlinger, M.; Kuijpers, M. H. G.; Braekmans, D. y Berger, D. 2017 . "Quantitative comparisons of the color of $\mathrm{CuAs}, \mathrm{CuSn}, \mathrm{CuNi}$ and CuSb alloys". Journal of Archaeological Sciences 88: 14-23. https://doi.org/10.1016/j.jas.2017.09.001
Montero Ruiz, I. 2018: "La procedencia del metal: consolidación de los estudios con isótopos de plomo en la Península Ibérica”. Revista de Arqueologia de Ponent, 28.

Montero Ruiz, I., García Heras, M. y López-Romero, E. 2007: “Arqueometría: cambios y tendencias actuales”. Trabajos de Prehistoria 64 (1): 23-40. https://doi.org/10.3989/tp.2007.v64.i1.92

Montero Ruiz, I., Martínez Navarrete, M. I. y Galán, E. 2016: “Objetos o materia prima: problemas en la interpretación de procedencias con análisis de isotopos de plomo". Boletín del Museo Arqueológico Nacional, 34: 81-98.

Montero-Ruiz, I.; Rafel, N.; Rovira, M. C.; Armada, X.-L.; Graells, R.; Hunt, M.;... y Santos, M. 2012: "El cobre de Linares (Jaén) como elemento vinculado al comercio fenicio en El Calvari de El Molar (Tarragona)". Menga 3: 167-186.

Müller, R.; Goldenberg, G.; Barttelheim, M.; Kunst, M. y Pernicka, E. 2007: "Zambujal and the beginning of metallurgy in southern Portugal". En S. La Niece, D. Hook y P. Craddock (eds.): Metals and mines. Studies in Archaeometallurgy. Archetype. Londres: 15-26.

Murillo-Barroso, M.; Montero-Ruiz, I.; Rafel, N.; Hunt Ortiz, M. A. y Armada, X-L. 2016: "Macro-regional scale of silver production in Iberia during the $1^{\text {st }}$ millennium $\mathrm{BC}$ in the context of Mediterranean contacts". Oxford Journal of Archaeology 35 (1): 75-100. https://doi.org/10.1111/ojoa.12079

Nocete, F. (ed.) 2004: Odiel: proyecto de investigación arqueológica para el análisis del origen de la desigualdad social en el Suroeste de la Península Ibérica. Monografías de Arqueología 19. Consejería de Cultura, Junta de Andalucía. Sevilla.

Northover, P. y Rychner V. 1998: "Bronze analysis: experience of a comparative programme”. En C. Mordant, M. Pernot y V. Rychner (eds.): L'atelier du bronzier en Europe 1. CTHS. París: 19-40.

Orfanou, V. y Rehren, Th. 2015: "A (not so) dangerous method: pXRF vs. EPMA-WDS analyses of copper-based artefacts". Archaeological and Anthropological Science 7 (3): 387-397. https://doi.org/10.1007/s12520-014-0198-z

Otto, H. y Witter, W. 1952: Handbuch der ältesten vorgeschichtlichen Metallurgie in Mitteleuropa. Johann Ambrosius Barth. Leipzig.

Pare, Ch. (ed.) 2000: Metals make the world go round: supply and circulation of metals in Bronze Age Europe. Oxbow Books. Oxford.

Pereira, F.; Silva, R. J. C.; Soares, A. M. M. y Araújo, M. F. 2012: “Estudo arqueometalúrgico de artefactos provenientes do Castro de Vila Nova de São Pedro (Azambuja, Portugal)". Estudos Arqueológicos de Oeiras 19: 163-172.

Pernicka, E. 1990: "Gewinnung und Verbreitung der Metalle in prähistorischer Zeit”. Jarhbuch des Römisch-Germanischen Zentralmuseums 37 (1): 21-129.

Pernicka, E. 2014: "Provenance determination of archaeological metal objects". En B.W. Roberts y C.P. Thornton (eds.): Archaeometallurgy in global perspective: methods and syntheses. Springer. Nueva York: 239-268.

Pollard, A. M.; Bray, P.; Gosden, C.; Wilson, A. y Hamerow, H. 2015: "Characterising copper-based metals in Britain in the first millennium AD: a preliminary quantification of metal flow and recycling". Antiquity 89: 697-713. https://doi.org/10.15184/aqy.2015.20

Radivojević, M.; Pendi, J.; Srejić, A.; Kora, M.; Davey, C.; Benzonelli, A.;... y Kamberović, Z. 2018: "Experimental design of the Cu-AsSn ternary colour diagram". Journal of Archaeological Science 90: 106-119. https://doi.org/10.1016/j.jas.2017.12.001

Radivojević, M. y Rehren, Th. 2015: "Paint it black: the rise of metallurgy in the Balkans". Journal of Archaeological Methods and Theory 23: 200-237. https://doi.org/10.1007/s10816-014-9238-3

Renzi, M. 2013: La Fonteta Guardamar de Segura, Alicante y la metalurgia fenicia de época arcaica en la Península Ibérica. Tesis Doctoral. Universidad Complutense de Madrid. Madrid. http://eprints.ucm.es/20078/

Renzi, M.; Rovira, S.; Rovira-Hortalà, M. C. y Montero Ruiz, I. 2013: "Questioning research on early iron in the Mediterranean". En J. Humphris y Th. Rehren (eds.): The World of Iron. Archetype. Londres: 178-187.

Renzi, M. y Rovira, S. 2015: "Las metalurgias fenicias”. En J. M. López Ballesta (ed.): Phicaria. III Encuentros Internacionales del Mediterráneo. Universidad Popular de Mazarrón. Murcia: 113-127. 
Rodríguez Bayona, M.; Nocete, F.; Sáez, R.; Nieto, J. M.; Inácio, N. M. de F. y Abril, D. 2010: "El 'barrio metalúrgico' de Valencina de la Concepción (Sevilla): procesos de producción vinculados a la manufactura de productos de cobre". En M. E. Sáiz, R. López Romero, M. A. Cano y J. C. Calvo (eds.): VIII Congreso Ibérico de Arqueometría. Actas (Teruel 2009): 207-218. Teruel.

Rovira, S. 1990: La metalurgia americana: análisis tecnológico de materiales prehispánicos y coloniales. Colección Tesis Doctorales 7/90, Universidad Complutense de Madrid. Madrid.

Rovira, S. 1994: "Pre-Hispanic goldwork from the Museo de América, Madrid: a new set of analyses". En D. A. Scott y P. Meyers (eds.): Archaeometry of Pre-Columbian sites and artifacts. Proceedings of a Symposium organized by de UCLA Institute of Archaeology and The Getty Conservation Institute (Los Angeles, California 1992): 323-350. Los Angeles.

Rovira, S. 1995: "Estudio arqueometalúrgico del depósito de la Ría de Huelva". En M. Ruiz-Gálvez (ed.): Ritos de paso y puntos de paso. La Ría de Huelva en el mundo de Bronce Final europeo. Complutum Extra 5, Universidad Complutense. Madrid: 33-57.

Rovira, S. 1998: "Metalurgia Campaniforme en España: resultados de quince años de investigación arqueometalúrgica". En M.-Ch. FrèreSautot (ed.): Paléométallurgie des cuivres. Actes du Colloque de Bourg-en-Bresse et Beaune (1997): 109-127. Montagnac.

Rovira, S. 2004: "Tekhnologiya vyplavki metalla i ego obrabotki". En E. N. Chernykh (ed.): Kargaly III. Selische Gorny: arkheologicheskie materialy. Tekhnologiya gorno-metallurgicheskogo proizvosdtva. Arkheobiologicheskie issledovaniya. Yazyki Slavianskoi Kultury. Moskva: 106-133 (en ruso en el original) ${ }^{3}$.

Rovira, S. 2016: "La metalurgia calcolítica en el suroeste de la Península Ibérica: una interpretación personal". Menga 7: 53-67.

Rovira, S. y Ambert, P. 2002a: "Les céramiques à réduire le minerai de cuivre: une technique métallurgique utilisée en Ibérie, son extension en France méridionale". Bulletin de la Société Préhistorique Française 991: 105-126. https://doi.org/10.3406/bspf.2002.12609

Rovira, S. y Ambert, P. 2002b: "Vasijas cerámicas para reducir minerales de cobre en el Península Ibérica y en la Francia meridional”. Trabajos de Prehistoria 59 (1): 89-105. https://doi.org/10.3989/tp.2002.v59.i1.212

Rovira, S. y Delibes, G. 2005: "Tecnología metalúrgica Campaniforme en la Península Ibéricas: coladas, moldeado y tratamientos postfundición". En M.A. Rojo-Guerra, R. Garrido-Pena e I. García-Martínez de Lagrán (coord.): El Campaniforme en la Península Ibérica y su contexto europeo. Universidad de Valladolid. Valladolid: 495-512.

Rovira, S. y Gómez Ramos, P. 2003: Las primeras etapas metalúrgicas en la Península Ibérica. III. Estudios metalográficos. Taravilla. Madrid.

Rovira, S. y Montero Ruiz, I. 2013: "Iberia: technological development of prehistoric metallurgy". En S. Burmeister, S. Hansen, M. Kunst y N. Müller-Scheessel (eds.): Innovative technologies and social change in Prehistory and Antiquity. Studien aus den Forschungsclustern des Deutschen Archäologischen Instituts 12, Marie Leisdorf. Rahden/ Westf.: 231-239.

Rovira, S.; Montero Ruiz, I. y Consuegra, S. 1997: Las primeras etapas metalúrgicas en la Península Ibérica. I Análisis de materiales. Instituto Universitario Ortega y Gasset y Ministerio de Educación y Cultura. Madrid.

Rovira, S.; Renzi, M.; Moreno, A. y Contreras, F. 2015: “Copper slags and crucibles of copper metallurgy in the Middle Bronze Age site (El Argar Culture) of Peñalosa (Baños de la Encina, Jaen, Spain)”. En A. Hauptmann y D. Mondarressi-Tehrani (eds.): Archaeometallurgy in Europe III. Proceedings of the $3^{\text {rd }}$ International Conference (Bochum 2011): 355-362. Bochum.

Rovira i Port, J. 2012-2013: "Una nueva punta de jabalina segoviana de tipo Palmela atribuida erróneamente a la sepultura de Montilla". $O p$ pidum 8-9: 23-28.

Selimkhanov, I. R. 1982: “Arsenical Copper Age in H.H. Coghlan's works: and investigations in laboratory of the Institute of History of the Academy of Sciences of Azerbaijan SSR". Journal of the Historical Metallurgy Society 16 (2): 50-57.

Tylecote, R. F. 1979: A history of metallurgy. The Metals Society. Londres.

Tylecote, R. F. 1991: "Early copper base alloys: natural or man-made?". En J.-P. Mohen y Ch. Éluère (eds.): Découverte du metal. Picard. París: 213-222.

Warner, R. B. y Cahill, M. 2011: “Analysing ancient Irish gold: an assessment of the Hartmann database". The Journal of Irish Archaeology XX: 42-52.

Watson, P. J.; LeBlanc, S. A. y Redman, C. L. 1971: Explanation in Archaeology: an explicit scientific approach. Columbia University Press. Nueva York - Londres.

Zwicker, U.; Greiner, H.; Hofmann, K. H. y Reithinger, M. 1985: “Smelting, refining and alloying of copper and copper alloys in crucible-furnaces during prehistoric up to Roman time". En P. T. Craddock y M. J. Hughes (eds.): Furnaces and smelting technology in Antiquity. British Museum Occasional Paper 48. Londres: 103-115.

3 Rovira, S. 2004: “Technology of copper metallurgy". En E. N. Chernykh (ed.): Kargaly III. Gorny site: Archaeological materials. Technology of mining and metallurgy. Archaeobiological Studies. Languages of Slavonic Culture. Moscow: 106-133.

Trab. Prehist., 75, N. ${ }^{\circ}$ 2, julio-diciembre 2018, pp. 223-247, ISSN: 0082-5638 